This is the submitted version of the article:

Amorín-Ferré, L.; Busqué, F.; Bourdelande, J.L.; Ruiz-Molina, D.; Hernando, J.; Novio, F.. Encapsulation and release mechanisms in coordination polymer nanoparticles. Chemistry - A European Journal, (2013). 19. 51: 17508 - .

10.1002/chem. 201302662.

Available at: https://dx.doi.org/10.1002/chem.201302662 


\title{
Encapsulation and Release Mechanisms in Coordination Polymer Nanoparticles
}

\author{
Laura Amorín-Ferrée, ${ }^{[\mathrm{a}]}$ Félix Busqué, ${ }^{[\mathrm{a}]}$ José Luis Bourdelande, ${ }^{[\mathrm{a}]}$ Daniel Ruiz-Molina, ${ }^{[\mathrm{b}, \mathrm{c}]}$ Jordi \\ Hernando* ${ }^{[a]}$ and Fernando Novio ${ }^{*[b, c]}$
}

\begin{abstract}
The interplay of guest encapsulation and release mechanisms in nanoscale metal-organic vehicles and its effect on the drug delivery kinetics of these materials were investigated via a novel multidisciplinary approach. Two rationally-designed molecular guests were synthesised, which consist of a red-fluorescent benzophenoxazine dye convalently tethered to a coordinating catechol group and a protected, non-coordinating catechol moiety. This allowed loading of the
\end{abstract}

guests into compositionally and structurally equivalent coordination polymer particles through distinct encapsulation mechanisms: coordination and mechanical entrapment. The two types of particles delivered their fluorescent cargo with remarkably different kinetic profiles, which could be satisfactorily modelled considering degradation- and diffusioncontrolled release processes. This demonstrates that careful selection of the method of guest incorporation into coordination polymer nanoparticles allows selective tuning of the rate of drug delivery from these materials and, therefore, of the time window of action of the encapsulated therapeutic agents.

Keywords: metal-organic
frameworks $\bullet$ coordination polymer
nanoparticles • drug delivery $\bullet$
degradation-controlled release •
diffusion-controlled release

\section{Introduction}

Coordination polymer particles (CPPs) have recently emerged as a novel family of metal-organic materials formed by self-assembly of metal ions and polydentate bridging ligands. ${ }^{1,2}$ Together with crystalline metal-organic frameworks (MOFs), CPPs have been proposed for a large variety of applications owing to the intrinsic versatility of coordination chemistry, which allows the properties of the final materials to be rationally tailored by proper choice of

[a] L. Amorín-Ferré, Dr. F. Busqué, Dr. J. L. Bourdelande, Dr. J. Hernando

Departament de Química

Universitat Autònoma de Barcelona

Edifici C/n, Campus UAB

Cerdanyola del Vallès, 08193(Spain)

Fax: (+34) 935811265

E-mail: jordi.hernando@uab.cat

b] Dr. D. Ruiz-Molina, Dr. F. Novio

Institut Català de Nanociència i Nanotecnologia (ICN2)

Edifici ICN2, Campus UAB

Cerdanyola del Vallès, 08193(Spain)

Fax: (+ 34) 937372648

E-mail: fernando.novio@cin2.es

[c] Dr. D. Ruiz-Molina, Dr. F. Novio

Consejo Superior de Investigaciones Científicas (CSIC)

Edificio ICN2, Campus UAB

Cerdanyola del Vallès, 08193(Spain)

Supporting information for this article is available on the WWW under http://www.chemeurj.org/ or from the author. metals and ligands. ${ }^{3}$ Of special interest is the use of CPPs in medicine, which is predicted to have a broad impact in the fields of bioimaging and drug delivery. ${ }^{4,5,6}$ Since the pioneering work from Mirkin and co-workers in 2005, ${ }^{1}$ an increasing number of reports have indeed described the successful application of nanoscale coordination polymer particles to encapsulate and release therapeutic agents. ${ }^{6}$ Nonetheless, the use of CPPs for drug delivery is in its fledgling stage. A detailed rationalisation of guest encapsulation and release mechanisms is still required to understand the drug delivery kinetics of most CPPs and, consequently, to fully assess their potential use as nanocarriers for therapeutic purposes. While these issues have already been subject of extensive debate for biodegradable organic polymer vehicles as drug delivery systems, ${ }^{7,8,9}$ little attention has so far been paid to them in the case of the emerging CPP-based materials.

Incorporation of the active molecules in coordination polymer nanoparticles usually proceeds via two distinct strategies: (1) binding of the drug to the polymer framework as a CPP building block $^{10,11,12,13,14}$ and (2) mechanical entrapment of the therapeutic agent within the metal-organic matrix. ${ }^{15,16,17}$ Accordingly, drug release can take place though different mechanisms, namely slow particle degradation via surface erosion, fast diffusion processes and/or a combination of both. This scenario can be even more intricate if undesired desorption from the particle surface occurs. As a result, complex drug delivery profiles are often encountered in CPPs that preclude unambiguous elucidation of the relationship between encapsulation and release mechanisms. ${ }^{5,16}$

To share more light into this issue, we have envisioned the fabrication of morphologically equivalent CPPs bearing a fluorescent guest that can be either coordinated to the polymer backbone (M1) or physically encapsulated within the particle (M2). 
These two materials therefore represent excellent benchmark systems to comparatively investigate degradation- and diffusioncontrolled drug release processes in CPPs. A schematic representation of this approach is shown in Fig. 1. The molecular guest of choice for these studies is a red-fluorescent benzophenoxazine dye convalently linked to a coordinating catechol group, both in its non-protected (1) and protected forms (2). On the other side, cobalt nanoparticles with general composition [Co(bix)(3,5-dbsq)(3,5-dbcat)] were used as carriers, where bix is a flexible bisimidazole bridging ligand and 3,5-dbsq and 3,5-dbcat stand for the semiquinonate radical and catecholate forms of the 3,5di-tert-butylcatechol. ${ }^{15,16,18}$ Although analogous CPPs containing $\mathrm{Zn}^{2+}$ ions and bix ligands have already been reported and evaluated for drug delivery applications, ${ }^{15,16}$ the choice of $[\mathrm{Co}(\mathrm{bix})(3,5-$ dbsq)(3,5-dbcat)] nanoparticles is justified by: (1) the high affinity of catechol groups to coordinate to cobalt ions, which provided us with a simple way to incorporate the fluorescent guest to the polymer backbone in M1 without modification of the coordination sphere; (2) the well-known optical properties of $[\mathrm{Co}(3,5-\mathrm{dbsq})(3,5-$ dbcat)(N-N)] units, ${ }^{19}$ which must result in efficient fluorescence quenching of compounds $\mathbf{1}$ and $\mathbf{2}$ while they remain in the interior of the nanoparticles and, therefore, allow for selective detection of the released guest molecules; and (3) the valence tautomerism exhibited by $\left[\mathrm{Co}\right.$ (bix)(3,5-dbsq)(3,5-dbcat)] CPPs, ${ }^{18}$ which can be exploited to assess the morphological similarities between M1 and M2.

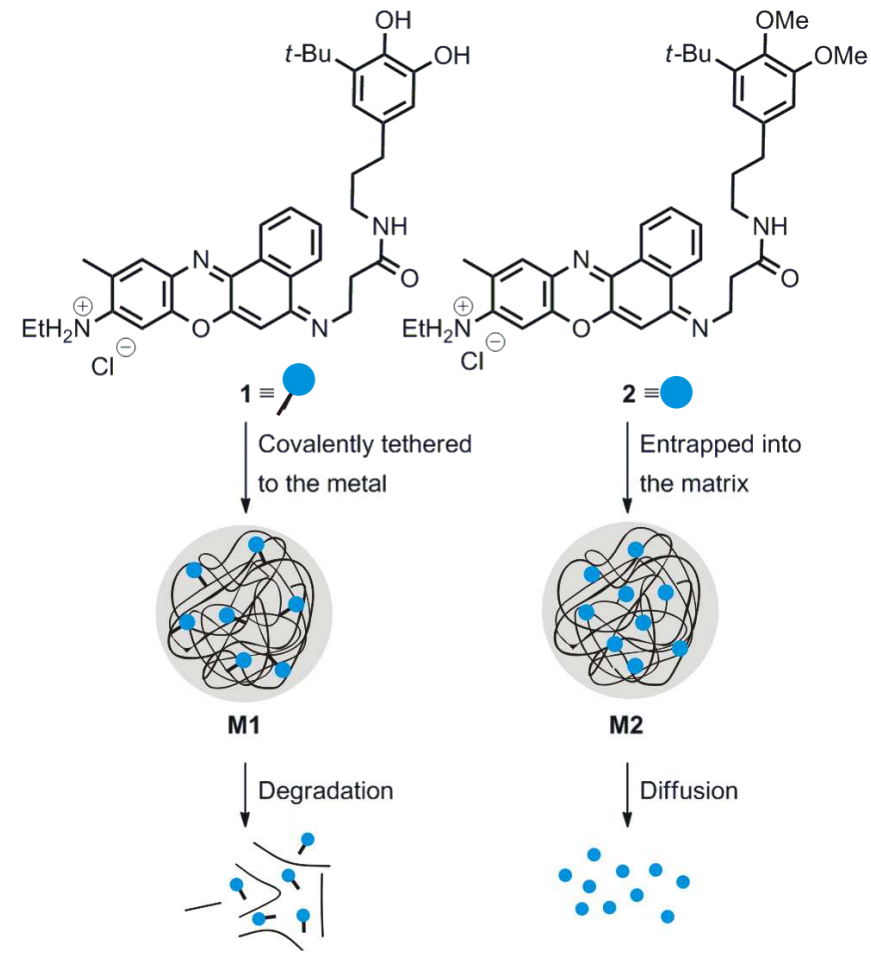

Figure 1. Chemical structures of fluorescent guest compounds $\mathbf{1}$ and 2, with which $\mathbf{M} \mathbf{1}$ and $\mathbf{M} 2$ coordination polymer particles were prepared to investigate degradation- and diffusion-controlled release from CPPs.

\section{Results and Discussion}

Synthesis and characterization of fluorescent guests 1 and 2. Scheme 1 shows the synthetic route followed to obtain $\mathbf{1}$ and $\mathbf{2}$. Briefly, the tert-butylation and subsequent allylic oxidation of commercial 2-methoxy-4-methylphenol gave known aldehyde $\mathbf{3}$ in
$97 \%$ yield, ${ }^{20}$ which is a common intermediate for both target compounds. At this point, synthetic pathways diverged, either temporally protecting the hydroxyl groups of the catechol moiety as the corresponding methoxymethylethers, foresighting to obtain compound 1, or permanently derivatizating them as the methyl ethers found in compound 2. Thus, known intermediate 4a was obtained from 3 by sequential demethylation with $\mathrm{BBr}_{3}$, and protection of the corresponding catechol with methoxymethylbromide (90\% overall yield). ${ }^{21}$ Methylation of the free hydroxyl of compound $\mathbf{3}$ gave previously described derivative 4b $(90 \%){ }^{22}$<smiles>COc1cc(C=O)cc(C(C)(C)C)c1OC</smiles><smiles>[R]Oc1cc(C=O)cc(C(C)(C)C)c1Oc1cc(C=CC(C)C)cc(C(C)(C)C)c1O[R]</smiles>

$$
\begin{array}{lll}
\text { 4a: } R=M O M & 5 a: R=M O M & 6 a: R=M O M \\
\text { 4b: } R=M e & 5 b: R=M e & 6 b: R=M e
\end{array}
$$<smiles>[R]Oc1cc(CCCNC(=O)CCNc2cccc3c(CCC)cccc23)cc(C(C)(C)C)c1[R2]</smiles>

$$
\begin{array}{ll}
\text { 7a: } R=M O M & \text { 8a: } R=M O M \\
\text { 7b: } R=M e & \text { 8b: } R=M e
\end{array}
$$<smiles>[R]Oc1cc(CCCNC(=O)CCN=c2cc3oc4cc(Cl)c(C)cc4nc-3c3ccccc23)cc(C(C)(C)C)c1[R]</smiles>

Scheme 1. Synthesis of fluorescent guests 1 and 2. (a) $t-\mathrm{BuOH}, \mathrm{H}_{3} \mathrm{PO}_{4}, 80{ }^{\circ} \mathrm{C}, 10 \mathrm{~h}$; (b) $\mathrm{Br}_{2}, t$-BuOH, rt, 4 h; (c) $\mathrm{BBr}_{3}, \mathrm{CH}_{2} \mathrm{Cl}_{2}, \mathrm{rt}, 3 \mathrm{~h}$; (d) MOMCl, DIPEA, DMAP, $\mathrm{CH}_{2} \mathrm{Cl}_{2}$, reflux, $24 \mathrm{~h}$; (e) $\mathrm{Me}_{2} \mathrm{SO}_{4}, \mathrm{~K}_{2} \mathrm{CO}_{3},(n-\mathrm{Bu})_{4} \mathrm{NI}, \mathrm{DMF}$, rt, $15 \mathrm{~h}$; (f) $\mathrm{Ph}_{3} \mathrm{PCHCN}$, toluene, reflux, $18 \mathrm{~h}$; (g) $\mathrm{H}_{2}$ (2 atm), $\mathrm{Pd} / \mathrm{C}$, EtOAc $18 \mathrm{~h}$; (h) $\mathrm{LiAlH}_{4}$, anh THF, addition at $0{ }^{\circ} \mathrm{C}$, then rt, $15 \mathrm{~h}$; (i) 3-(naphthalen-1-ylamino)propanoic acid, EDCI, DIPEA, $\mathrm{CH}_{2} \mathrm{Cl}_{2}, \mathrm{rt}, 18$ h; (j) $\mathrm{N}$-ethyl-5-hydroxy-2-methyl-4-nitrosobenzenaminium chloride, $\mathrm{HCl}, \mathrm{MeOH}$, reflux, $2 \mathrm{~h}$.

Next synthetic steps are analogous for both target compounds. The Wittig reaction between aldehydes $\mathbf{4 a}$ and $\mathbf{4 b}$ and the stabilized phosphorane 2-(triphenylphosphoranylidene) acetonitrile afforded the corresponding olefins $\mathbf{5 a}$ (96\% yield) and $\mathbf{5 b}$ ( $72 \%$ yield), as mixtures of $Z$ - and $E$ - isomers. Successive hydrogenation of the alkene moieties, at high pressure of $\mathrm{H}_{2}$ under $\mathrm{Pd} / \mathrm{C}$ catalyst, and nitriles, with $\mathrm{LiAlH}_{4}$, furnished amines $7 \mathbf{a}$ and $7 \mathbf{b}$ in 61 and $51 \%$ overall yields for both reduction reactions, respectively. After this, troublesome formation of amides $\mathbf{8 a}$ ( $31 \%$ yield) and $\mathbf{8 b}$ (35\% yield) 
was achieved by reaction between amines $7 \mathbf{a}$ and $7 \mathbf{b}$ and $3-$ (naphthalen-1-ylamino) propanoic acid, using 1-ethyl-3-(3-dimethyl aminopropyl) carbodiimide (EDCI) as coupling agent. ${ }^{23}$ Compounds $\mathbf{1}$ and $\mathbf{2}$ were finally obtained by reaction between naphthylamines 8a and $\mathbf{8 b}$ and $N$-ethyl-5-hydroxy-2-methyl-4nitrosobenzenaminium chloride in methanol, under acidic catalyst and reflux temperature $(45 \%$ and $35 \%$ yield for $\mathbf{1}$ and $\mathbf{2}$, respectively). ${ }^{24}$ Importantly, this last step did not only allow the benzophenoxazine dye group of both fluorescent guests to be constructed, but also concomitant cleavage of the methoxymethylethers to eventually obtain compound $\mathbf{1}$.

Once synthesised, the optical properties of compounds $\mathbf{1}$ and $\mathbf{2}$ were investigated in detail. Fig. 2 plots the absorption and fluorescence emission spectra of these species in methanol, which are mainly governed by the optical transitions corresponding to their benzophenoxazine dye unit. As a result, compounds 1 and $\mathbf{2}$ display equivalent absorption $\left(\lambda_{\max , 1}=625 \mathrm{~nm}, \lambda_{\max , 2}=626 \mathrm{~nm}\right.$, $\left.\varepsilon_{\max , 1}=\varepsilon_{\max , 2}=4.8 \times 10^{4} \mathrm{M}^{-1} \mathrm{~cm}^{-1}\right)$ and emission bands $\left(\lambda_{\max , 1}=643 \mathrm{~nm}\right.$, $\lambda_{\max , 2}=645 \mathrm{~nm}$ ), which resemble those reported for similar derivatives. ${ }^{25}$ Importantly, covalent tethering of the benzophenoxazine unit to catechol and $o$-methoxyanisole groups in 1 and $\mathbf{2}$ does not quench its inherent emissive behaviour, the resulting dyads thus presenting high fluorescence quantum yields $\left(\Phi_{\mathrm{f}, 1}=0.40, \Phi_{\mathrm{f}, 2}=0.41\right)$. Together with their long-wavelength absorption and emission spectra, this makes compounds $\mathbf{1}$ and $\mathbf{2}$ ideal fluorescent reporters to monitor guest release from CPPs as well as particle degradation.

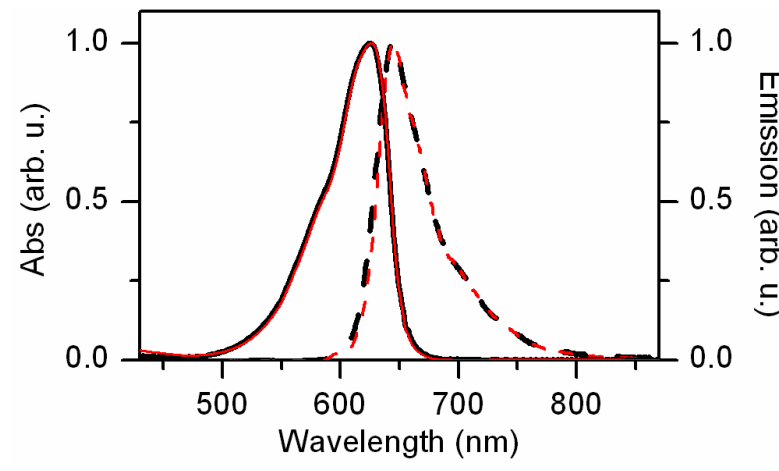

Figure 2. Absorption (solid lines) and fluorescence emission spectra (dashed lines) of fluorescent guests $\mathbf{1}$ (black) and $\mathbf{2}$ (red).

Fabrication and characterization of M1 and M2 CPPs. Adapting an experimental procedure previously published by us, ${ }^{18}$ coordination polymer particles M1 and M2 were prepared by reaction of $\mathrm{Co}^{2+}$ ions with the ditopic ligands 1,4-bis(imidazol-1ylmethyl)benzene and 3,5-di-tert-butylcatechol in the presence of guest compounds 1 and $\mathbf{2}$ (Fig. 3a). This led to the formation of [Co(bix)(3,5-dbsq)(3,5-dbcat)] polymers, which readily precipitated as nanoparticles due to their low solubility in the reaction medium. The resulting CPPs were subsequently collected by centrifugation, washed with 5:1 water:ethanol mixtures until no red fluorescence was observed in the supernatant solution, and finally dried. For comparison purposes, guest-free coordination polymer nanoparticles (M0) were also prepared using this methodology. Noticeably, very small amounts of compounds $\mathbf{1}$ and $\mathbf{2}$ were used in the preparation of materials M1 and M2 (catechol:guest molar ratio 100:1). With such low doping loads we intended to minimize the effect of the fluorescent guests on the formation of the nanoparticles, which should allow us to unambiguously ascribe the differences observed in their release profiles to the occurrence of distinct guest incorporation and delivery mechanisms.
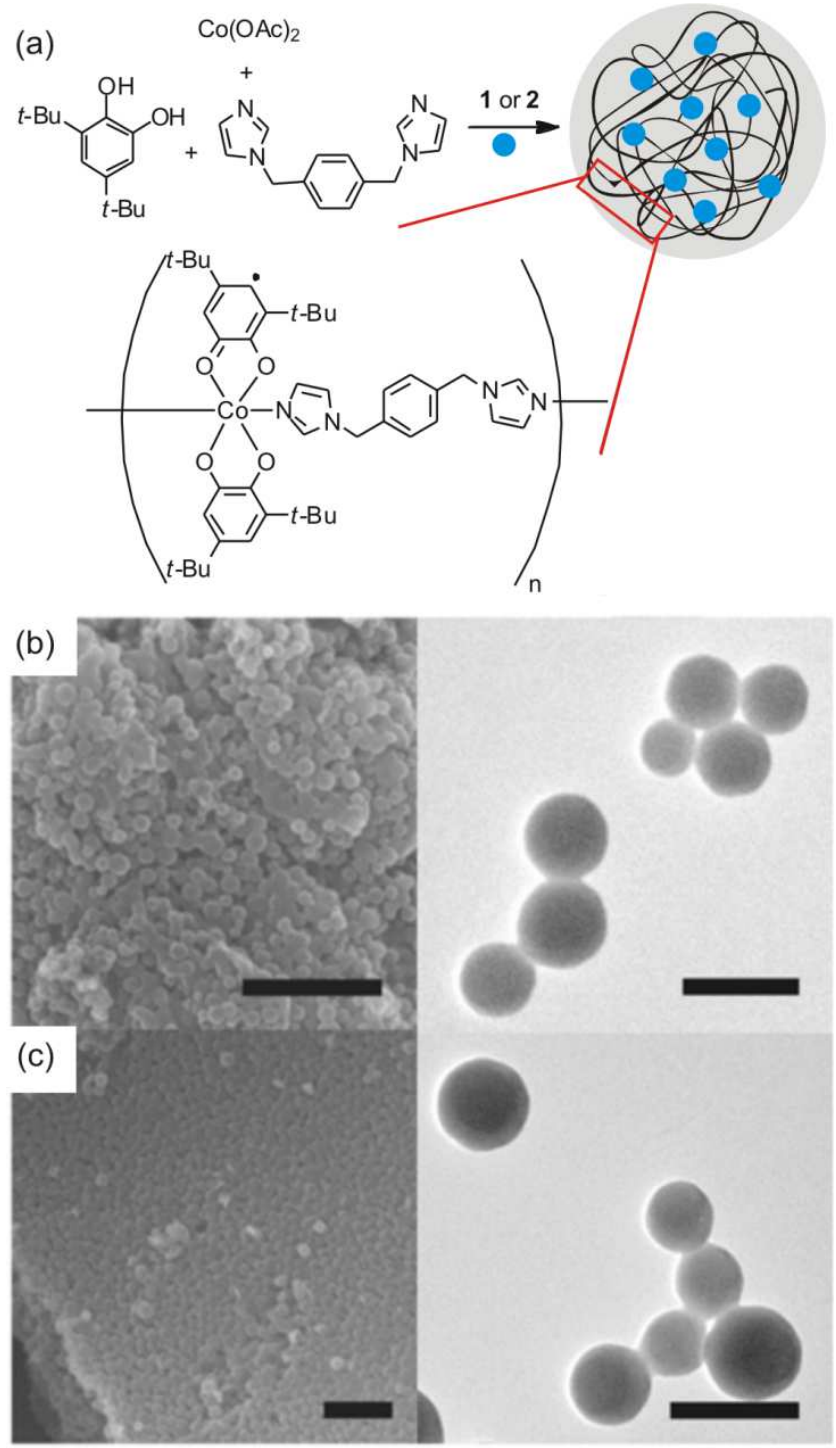

Figure 3. (a) Schematic synthesis of CPPs doped with fluorescent guests 1 and 2. (b-c) SEM (left) and TEM (right) images of M1 (b) and M2 (c) particles. Scale bars for SEM are $1 \mu \mathrm{m}$ and for TEM are $200 \mathrm{~nm}$.

Formation of morphologically equivalent CPPs was indeed revealed by scanning (SEM) and transmission (TEM) electron microscopy images (Fig. 3b-c and see also Fig. S1 in the Supporting Information). In all cases nanometer-sized solid particles with spherical shapes and rather uniform and similar diameters $(195 \pm 38$, $152 \pm 22$ and $185 \pm 37 \mathrm{~nm}$ for M0, M1 and M2, respectively) were obtained. X-ray diffraction experiments confirmed the amorphous character of these materials, while spectroscopic characterisation upon dissolution of the nanoparticles in degassed methanol revealed the occurrence of different electronic absorption bands arising from their constituent functional units (Fig. 4a). Thus, an absorption band at $\lambda \sim 625 \mathrm{~nm}$ was selectively found in the spectra of M1 and M2, which corresponds to the fluorescent benzophenoxazine moiety loaded in these materials. On the contrary, the other absorption bands at $\lambda \sim 400,590$ and $700 \mathrm{~nm}$ were not only encountered in the spectra of M1 and M2, but also observed for guest-free M0. These can be ascribed to intraligand and metal-to-ligand/ligand-to-metal 
charge transfer electronic transitions of the $[\mathrm{Co}(\mathrm{bix})(3,5$-dbsq) $(3,5-$ dbcat)] system. ${ }^{26}$ Noticeably, these absorption bands corresponding to the coordination complex units expand all over the UV, vis and NIR regions, and therefore they overlap with the emission spectrum of the benzophenoxazine dye (see Fig. 2a). Consequently, efficient quenching of dye fluorescence via resonant energy transfer processes is expected in the interior of the nanoparticles, where these moieties will be located at the near proximity of coordination complex units regardless of whether they are directly coordinated to the metal centre or physically encapsulated within the polymer network. Indeed, no red fluorescence could be measured for M1 and M2 particles in the solid state, which confirms effective quenching of the emission of the loaded guests (Fig. 4b).
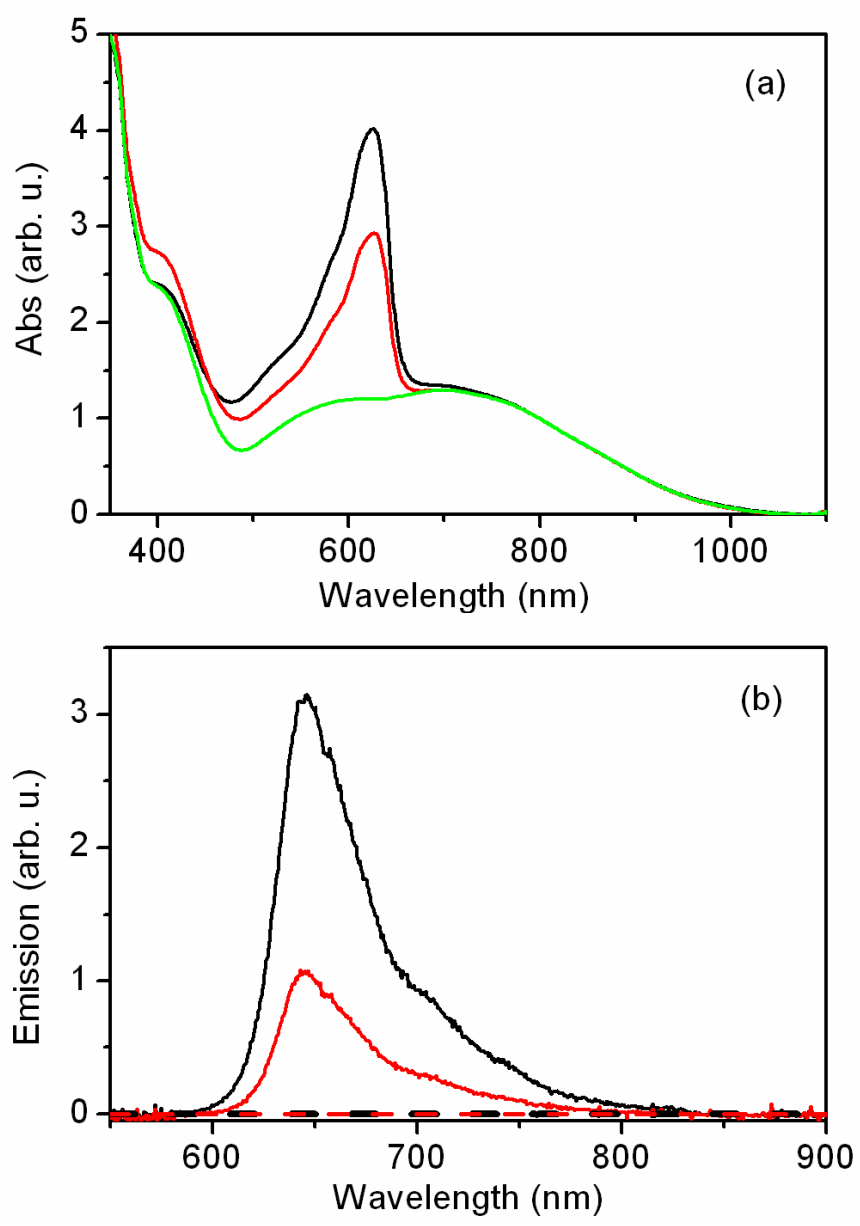

Figure 4. (a) Absorption spectra of M0 (green), M1 (black) and M2 (red) in degassed $\mathrm{MeOH}$. (b) Fluorescence emission spectra recorded in degassed $\mathrm{MeOH}$ (dashed lines) and non-degassed $\mathrm{MeOH}$ (solid lines) of M1 (black) and M2 (red).

Fluorescence quenching is however inhibited upon guest release and CPP degradation, which allowed us to monitor the delivery of the particle cargo by means of highly sensitive emission measurements (vide infra). This was demonstrated by measuring the optical properties of M0, M1 and M2 in non-degassed methanol, where particle dissolution is followed by coordination polymer degradation via ligand exchange and concomitant oxidation of the catecholate and semiquinone groups. This leads to disappearance of the absorption bands associated to the $[\mathrm{Co}(\mathrm{bix})(3,5-\mathrm{dbsq})(3,5-$ dbcat)] coordination polymers as well as pronounced growth of the band at $\lambda \sim 400 \mathrm{~nm}$ corresponding to the quinone species resulting from catecholate and semiquinone degradation (see Fig. S2 in the
Supporting Information). ${ }^{27}$ Accordingly, no energy transfer processes are expected under such conditions and an enormous increase in benzophenoxazine emission was indeed measured (Fig. $4 \mathrm{~b})$. The absorption measurements in non-degassed methanol were also used to quantify the encapsulation efficiencies for the preparation of dye-doped $\mathbf{M 1}$ and $\mathbf{M} 2$ particles. Interestingly, higher values were obtained for M1 $(\sim 20 \%)$ than for M2 $(\sim 10 \%)$ under equivalent experimental conditions, which indicates that incorporation of the fluorescent guest bearing a coordinating catechol moiety is significantly more effective.

Valence tautomerism of M1 and M2 CPPs. The amorphous nature of M1 and M2 nanoparticles precludes any accurate structural characterisation by classical diffraction techniques. Nevertheless, we exploited the valence tautomerism (VT) behaviour shown by [Co(bix)(3,5-dbsq)(3,5-dbcat)] $\mathrm{CPPs}^{18,19}$ to investigate the structural similarities between M1 and M2. These systems might interconvert reversibly between the low-spin $l s$-[Co' ${ }^{\text {III }}$ (bix $\left.)(3,5-\mathrm{dbsq})(3,5-\mathrm{dbcat})\right]$ and high-spin $h s-\left[\mathrm{Co}^{\mathrm{II}}\right.$ (bix) $\left.(3,5-\mathrm{dbsq})_{2}\right]$ tautomers by intramolecular metal-ligand electron transfer, a process that can be selectively monitored by temperature dependent measurements of magnetic susceptibility.

Fig. 5 plots the results obtained in those measurements for M0, M1 and M2. In all cases, an abrupt change in effective magnetic moment $\left(\mu_{\text {eff }}\right)$ is observed around $300 \mathrm{~K}$, which is consistent with valence-tautomeric interconversion from low- to high-spin states for a large fraction of molecules in the nanoparticles. ${ }^{18}$ Importantly, the occurrence of valence tautomerism and the actual profile of the corresponding $\mu_{\text {eff }}$ vs $T$ plot is not only highly sensitive to metal complex composition and structure, but also to the local environment. ${ }^{19}$ In other words, the same complex may exhibit or not VT, or the low-spin-to-high-spin conversion might take place at different temperatures depending on structural and environmental parameters. Therefore, the extremely similar magnetic behaviour encountered for M0, M1 and M2 clearly indicates that they must be formed by equivalent coordination polymers in rather comparable phases.

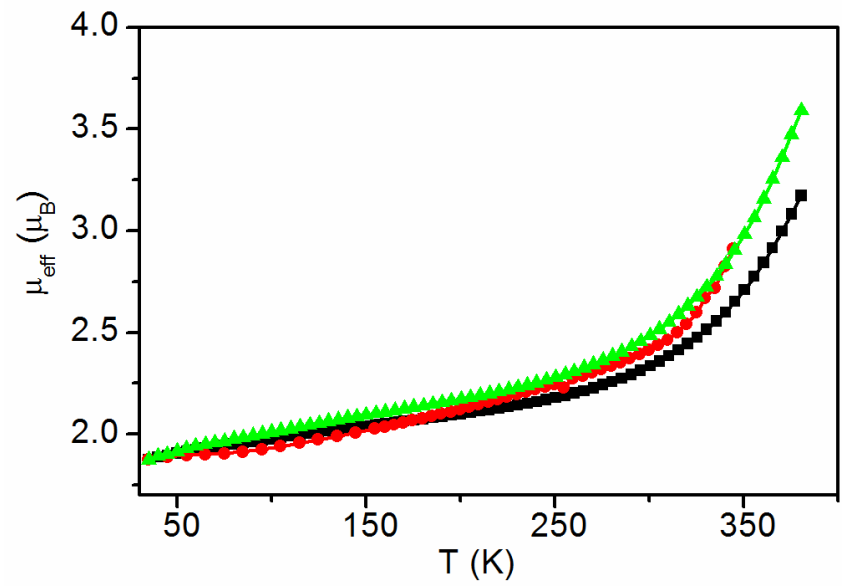

Figure 5. $\mu_{\text {eff }}$ values as function of temperature for M0 (green), M1 (black) and M2 (red) CPPs.

Guest release mechanisms. To investigate guest release from M1 and M2, colloidal suspensions were prepared in phosphate buffered saline solutions $(\mathrm{PBS})$ at $\mathrm{pH}=7.4$, placed in a dialysis bag (cut-off molecular weight: $3500 \mathrm{Da}$ ) at $37^{\circ} \mathrm{C}$, and finally dialysed against PBS for 100 hours. Relative cumulative release profiles were then 
measured by monitoring the fluorescence of the dialysis bath solution in time. In addition, the solid material remaining in the dialysis bag after 100 hours was dissolved in methanol and characterised by absorption spectroscopy, which allowed us to determine the absolute release efficiency of the dialysis experiment. Fig. 6 plots the cumulative release profiles measured for M1 and M2 under these experimental conditions. Both exhibit very high release efficiencies after 100 hours $(\sim 90 \%)$ with no "burst effects" associated to undesired desorption of guest molecules physisorbed onto the nanoparticle surface. However, the release kinetics measured for these materials were found to be strikingly different. In the case of $\mathbf{M 2}$, the delivery process was nearly completed after 8 $\mathrm{h}\left(\mathrm{t}_{1 / 2} \sim 1.2 \mathrm{~h}\right)$, a behaviour resembling that already reported for the release of anticancer drugs mechanically entrapped in analogue [Zn(bix)] CPPs. ${ }^{16}$ In contrast, a much slower process was observed for M1, which required about $100 \mathrm{~h}$ for completion $\left(\mathrm{t}_{1 / 2} \sim 11 \mathrm{~h}\right)$.

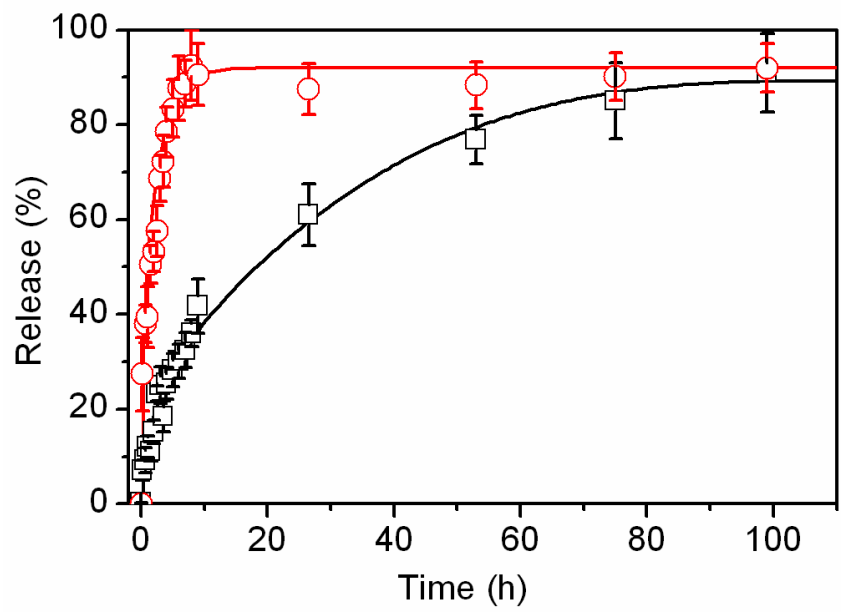

Figure 6. Guest release profiles of fluorescent guest molecules from M1 (black) and M2 (red) at $37{ }^{\circ} \mathrm{C}$, which were averaged over 4 independent experiments. Solid lines correspond to fits of the experimental data as described in the text.

On the basis of the non-coordinating nature of the encapsulated guest, the release profile of $\mathbf{M 2}$ at $37^{\circ} \mathrm{C}$ was fitted with a purely diffusion-controlled model of drug delivery. In particular, we considered the use of equation (1), which was derived for drug delivery via Fickian diffusion from spherical particles with homogenous and low-doping loads that do not significantly swell or degrade during the release process: ${ }^{28}$

$$
M_{t}=M_{\infty}\left(1-\frac{6}{\pi^{2}} \sum_{n=1}^{\infty} \frac{1}{n^{2}} \exp \left(-\frac{D n^{2} \pi^{2} t}{R^{2}}\right)\right)
$$

In this equation, $M_{t}$ and $M_{\infty}$ represent the cumulative absolute amounts of guest released at time $t$ and infinity, $R$ is the radius of the particles and $D$ is the apparent diffusion constant of the drug within the system. $D$ is the only variable parameter in this model, which is taken to remain constant throughout the release process by neglecting swelling and degradation effects on the structure of the polymeric drug carrier.

As observed in Fig. 6, a rather satisfactory fit of the experimental release kinetics of M2 was obtained using equation (1). Therefore, the delivery of the mechanically-entrapped fluorescent guest must be governed by a time-independent diffusion mechanism $(D=$ $\left.6.9 \times 10^{-19} \mathrm{~m}^{2} \mathrm{~s}^{-1}\right)$, which indicates that the influence of degradation processes on the release kinetics is negligible in this case even though it takes place. This is proven by Fig. 7, which displays SEM images of M2 nanoparticles suspended in aqueous media at $37^{\circ} \mathrm{C}$ for $0,5,26$ and $100 \mathrm{~h}$. While most particles preserved their spherical shape after $5 \mathrm{~h}$, extensive surface erosion and an increasing amount of non-structured material is observed in the SEM images registered at 26 and $100 \mathrm{~h}$. This confirms CPP degradation, which however takes place at a longer time scale than guest diffusion from the nanoparticles at $37^{\circ} \mathrm{C}$. This is in contrast with other systems for which clearly different delivery phases are observed that are ascribed to the occurrence of sequential fast diffusion and slow degradation processes. ${ }^{7-9}$
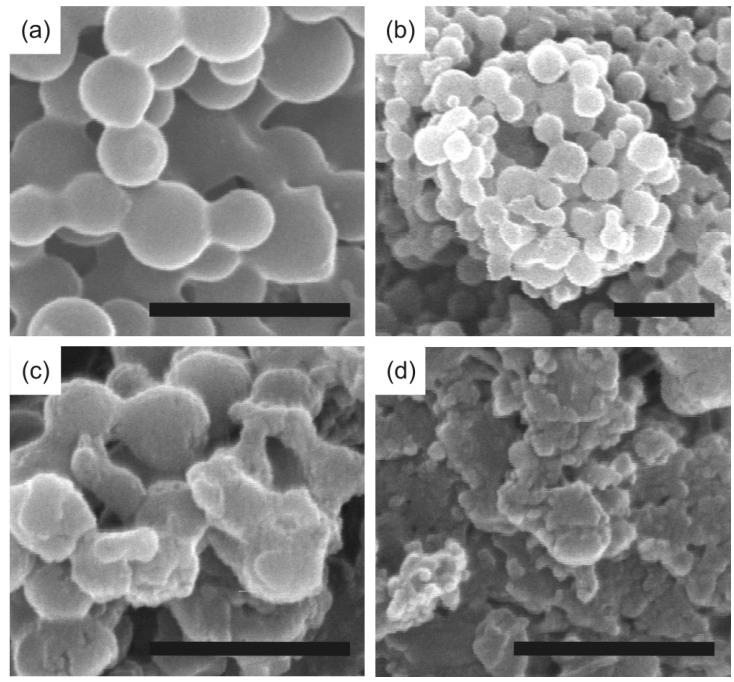

Figure 7. SEM images of $\mathbf{M} 2 \mathrm{CPPs}$ suspended at $37^{\circ} \mathrm{C}$ in aqueous media for (a) $0 \mathrm{~h}$, (b) $5 \mathrm{~h}$, (c) $26 \mathrm{~h}$ and (d) $100 \mathrm{~h}$. Scale bars are $500 \mathrm{~nm}$.

The release profile obtained for $\mathbf{M} 1$ at $37^{\circ} \mathrm{C}$ was also tentatively fitted with single-mechanism models, which in this case should solely account for degradation-controlled delivery. However, poor agreement between the experimental and fitted release profiles was obtained regardless of using surface-degradation ${ }^{29}$ or bulkdegradation ${ }^{30}$ models of drug delivery. This suggests the occurrence of a more complex release process, which we attempted to model by assuming simultaneous delivery via degradation and diffusion processes. In this scenario, degradation-controlled release should apply for all guest molecules coordinated to the polymeric backbone, while those that remain unbound but physically entrapped within the metal-organic matrix should be preferentially delivered by fast diffusion processes. Based on the previous results obtained for $\mathbf{M} 2$ and analogue $[\mathrm{Zn}(\mathrm{bix})] \mathrm{CPPs},{ }^{16}$ equation (2) was derived to account for such situation:

$$
\begin{aligned}
M_{t}=M_{\infty} & \left(b\left(1-\frac{6}{\pi^{2}} \sum_{n=1}^{\infty} \frac{1}{n^{2}} \exp \left(-\frac{D n^{2} \pi^{2} t}{R^{2}}\right)\right)\right. \\
& \left.+(1-b)\left(1-\left(1-\frac{k_{d} t}{(1-b) C_{0} R}\right)^{3}\right)\right)
\end{aligned}
$$

The first term in this equation corresponds to the Fickian diffusion model already applied to M2, where $b$ is the fraction of guest molecules that lie mechanically entrapped within M1 particles. As previously discussed, this model assumes that the diffusioncontrolled release of guest molecules takes place before significant degradation of the polymer matrix occurs, which allows the particle 
radius and the apparent guest diffusion constant to be considered time independent. This assumption is not only supported by the behaviour observed for M2, but also by the similar results obtained when monitoring the degradation process of M1 nanoparticles at $37^{\circ} \mathrm{C}$ in water media using SEM (see Fig. S3 in the Supporting Information). The second term in equation (2) corresponds to an empirical model that has been developed for degradation-controlled drug delivery from spherical particles via surface erosion, ${ }^{29}$ which is indeed the degradation mechanism reported for analogue $[\mathrm{Zn}(\mathrm{bix})]$ CPPs at physiological conditions. ${ }^{16}$ In this expression $(1-b)$ is the fraction of guest molecules coordinated to the metal centres in M1, $k_{d}$ is the surface erosion rate constant, $C_{0}$ is the total initial concentration of the guest in the polymer matrix $\left(7.2 \times 10^{-4} \%(\mathrm{w} / \mathrm{w})\right)$ and $R$ is the initial radius of the nanoparticles.

To fit equation (2) to the guest release profile measured for M1 at $37^{\circ} \mathrm{C}$, only two variable parameters were considered: $b$ and $k_{\mathrm{d}}$. To test the consistency of our model, $D$ was directly taken from the previous fit of M2 delivery kinetics, a rather plausible constraint based on the very similar structures of the guest compounds and coordination polymer particles investigated in this work. As observed in Fig. 6, a good agreement was encountered between the experimental and fitted release profiles of M1 even under such assumption, which proves the validity of our treatment $\left(b=0.26, k_{d}\right.$ $\left./\left(C_{0} R\right)=1.7 \times 10^{-6} \mathrm{~s}^{-1}\right)$. From this we conclude that most guest molecules in M1 nanoparticles (74\%) are directly bound to the polymer matrix, which are therefore released by slow degradation of the material. Nevertheless, a significant fraction of them $(26 \%)$ are not coordinated to cobalt ions despite presenting free catechol groups, but they were physically encapsulated during the formation of the particles. Accordingly, they are delivered via a fast timeindependent diffusion mechanism similar to that encountered for M2 CPPs.

Additional guest release experiments were performed at $60^{\circ} \mathrm{C}$ aiming at investigating the temperature dependence of the delivery processes in these materials (see Fig. S4 in the Supporting Information). In deep contrast to what had been observed at $37^{\circ} \mathrm{C}$, no significant differences were found between the release profiles measured for M1 and M2 at this temperature. In both cases, complete delivery of the fluorescence guests is observed at $\sim 5 \mathrm{~h}$, revealing the occurrence of much faster release processes. This suggests that degradation kinetics enormously accelerates at $60^{\circ} \mathrm{C}$, which must become at least comparable to guest diffusion rates. As a matter of fact, we expect the release profiles of M1 and M2 CPPs at these conditions to be mainly governed by degradation processes, which indicates that both the guest delivery kinetics and mechanisms of these materials can be dramatically altered by temperature control.

\section{Conclusion}

In this work we report a novel rational approach to investigate the relationship between guest encapsulation and release mechanisms for metal-organic nanoparticles. By proper design of the guest compounds and particle formation conditions, two types of coordination polymer particles were prepared that (1) are compositionally and structurally equivalent, and (2) were loaded with the same fluorescent guests using different encapsulation processes. As a result, the release of their fluorescent cargo at physiological conditions proceeds via distinct mechanisms that converge upon increasing the temperature. Physically encapsulated guest molecules are delivered by fast time-independent diffusion processes, while the release of coordinated guest moieties is governed by slow particle degradation. This leads to remarkably different guest release profiles for the CPPs prepared, which demonstrates that the kinetics of drug delivery can be selectively tuned up to many hours by appropriate choice of the mechanism of incorporation of the therapeutic agent into the polymeric nanocarrier. This results open new venues for the future use of CPPs in medicine.

\section{Experimental Section}

Materials and characterisation: All reactants and reagents were purchased from Sigma-Aldrich and used as received. Solvents were purchased from Scharlab and used as received. Dialysis bags were purchased from Orange Scientific.Infrared spectra were recorded on a Bruker Tensor 27 spectrometer equipped with a Golden Gate Single Reflection Diamond ATR (Attenuated Total Reflectance) accessory. High resolution mass analyses were performed on an ESI-QTOF Bruker Daltonics micrOTOF-Q spectrometer. NMR spectra were recorded on a Bruker ARX $400\left(400 \mathrm{MHz}\right.$ for ${ }^{1} \mathrm{H}$ NMR and $100 \mathrm{MHz}$ for ${ }^{13} \mathrm{C}$ NMR). The spectra are given in $\delta(\mathrm{ppm})$ using the signal of the residual non-deuterated solvent molecules as reference. Absorption spectra were recorded on a Hewlett Packard 8453 spectrophotometer. HPLC or spectroscopy quality solvents were used. Emission spectra were measured by means of a custom-made spectrofluorimeter, where a cw He-Ne REO laser $\left(\lambda_{\text {exc }}=594 \mathrm{~nm}\right)$ was used as excitation source and the emitted photons were detected in an Andor ICCD camera coupled to a spectrograph. HPLC or spectroscopy quality solvents were used. Fluorescence quantum yields were determined using Nile Blue A in ethanol solution as reference $\left(\Phi_{f}=0.27\right)$. $^{31}$ SEM measurements were registered on a HITACHI S-570 microscope (accelerating voltage $0.5-30 \mathrm{kV}$ ). TEM measurements were carried out on a HITACHI-7000 microscope operating at $125 \mathrm{kV}$

Synthesis of compound 4a: This compound was prepared according to ref. [21] with some modifications. Demethylation: To a solution of $\mathbf{3}(0.845 \mathrm{~g}, 4 \mathrm{mmol})$ in $\mathrm{CH}_{2} \mathrm{Cl}_{2}$ (30 $\mathrm{mL}$ ) cooled down in a liquid nitrogen bath, $4 \mathrm{~mL}$ of $1 \mathrm{M}$ solution of $\mathrm{BBr}_{3}$ in $\mathrm{CH}_{2} \mathrm{Cl}_{2}$ were added dropwise. Next, the reaction was allowed to proceed at room temperature for $2 \mathrm{~h}$. The reaction mixture was poured in $40 \mathrm{ml}$ distilled water and the resulting aqueous layer was extracted twice with $\mathrm{CH}_{2} \mathrm{Cl}_{2}(30 \mathrm{~mL})$. The organic extracts were dried with $\mathrm{MgSO}_{4}$ and the solvent evaporated under vacuum to afford the demethylated compound as a yellowish solid $(0.698 \mathrm{~g}, 90 \%)$. This compound was used in the next step without further purification. Protection of the catechol: To a solution of this intermediate $(0.492 \mathrm{~g}, 2.54 \mathrm{mmol})$ in $\mathrm{CH}_{2} \mathrm{Cl}_{2}(8 \mathrm{~mL})$ cooled down in a water bath, the following compounds were added dropwise: DIPEA ( $2.7 \mathrm{~mL}, 15.5 \mathrm{mmol})$, DMAP (30 $\mathrm{mg}, 0.22 \mathrm{mmol})$ and methoxymethyl bromide $(0.65 \mathrm{~mL}, 8.02 \mathrm{mmol})$. The solution was heated under reflux for $8 \mathrm{~h}$. The reaction mixture was treated with water $(15 \mathrm{~mL})$ and the resulting aqueous layer was extracted twice with $\mathrm{CH}_{2} \mathrm{Cl}_{2}(15 \mathrm{~mL})$. The organic extracts were dried with $\mathrm{MgSO}_{4}$ and the solvent evaporated under vacuum. Crude was purified by flash chromatography using hexanes and ethyl acetate $(4: 1, \mathrm{v} / \mathrm{v})$ to afford $4 \mathbf{a}$ $(0.716 \mathrm{~g}, 100 \%)$ as a yellowish oil. ${ }^{1} \mathrm{H}$ RMN (400 MHz, $\left.\mathrm{CDCl}_{3}\right): \delta=9.87(\mathrm{~s}, 1 \mathrm{H}), 7.55$ $(\mathrm{s}, 2 \mathrm{H}), 5.31(\mathrm{~s}, 2 \mathrm{H}), 5.23(\mathrm{~s}, 2 \mathrm{H}), 3.66(\mathrm{~s}, 3 \mathrm{H}), 3.52(\mathrm{~s}, 3 \mathrm{H}), 1.45 \mathrm{ppm}(\mathrm{s}, 9 \mathrm{H}) .{ }^{13} \mathrm{C}$ RMN $\left(100 \mathrm{MHz}, \mathrm{CDCl}_{3}\right): \delta=191.5,151.9,150.4,144.0,131.5,123.8,114.5,99.4$, 95.4, 57.9, 56.6, 35.4, $30.3 \mathrm{ppm}$. IR (ATR): $v=3076.2,2953.3,2905.4,2826.8,1690.1$, $1578.5 \mathrm{~cm}^{-1}$. HRMS (ESI-QTOF): $\mathrm{m} / z$ calcd for $\mathrm{C}_{15} \mathrm{H}_{22} \mathrm{NaO}_{5}$ : 305.1359; found: 305.1356 .

Synthesis of 4b: This compound was prepared according to ref. [22] with some modifications. To a solution of 3 (3.5 g, $16.8 \mathrm{mmol})$ in DMF $(100 \mathrm{~mL}), \mathrm{K}_{2} \mathrm{CO}_{3}(6.95 \mathrm{~g}$, $50.4 \mathrm{mmol})$ and $N, N, N$-tributyl-1-butanaminium iodide $(270 \mathrm{mg}, 0.73 \mathrm{mmol})$ were added. The reaction mixture was stirred for $2 \mathrm{~h}$ at room temperature. After this time, $\mathrm{Me}_{2} \mathrm{SO}_{4}(3.2 \mathrm{~mL}, 33.6 \mathrm{mmol})$ was added dropwise and the mixture was allowed to react for $16 \mathrm{~h}$. The resulting mixture was treated with water $(100 \mathrm{~mL})$ and the aqueous layer was extracted four times with EtOAc $(50 \mathrm{~mL})$. The organic extracts were dried with $\mathrm{MgSO}_{4}$ and the solvent evaporated under vacuum to afford $\mathbf{4 b}(3.36 \mathrm{~g}, 90 \%)$ as a dark green oil. ${ }^{1} \mathrm{H}$ RMN (400 MHz, $\left.\mathrm{CDCl}_{3}\right): \delta=9.91(\mathrm{~s}, 1 \mathrm{H}), 7.48(\mathrm{~d}, J=1.9 \mathrm{~Hz}, 1 \mathrm{H}), 7.38$ (d, $J=1.9 \mathrm{~Hz}, 1 \mathrm{H}), 3.97$ (s, 3H), 3.94 (s, 3H), $1.44 \mathrm{ppm}$ (s, 9H).

Synthesis of 5a. To a solution of $4 \mathrm{a}(1.559 \mathrm{~g}, 5.53 \mathrm{mmol})$ in toluene $(45 \mathrm{~mL})$, (triphenylphosphoranylidene)acetonitrile $(2.070 \mathrm{~g}, 6.87 \mathrm{mmol})$ was added. The reaction mixture was heated under reflux for $12 \mathrm{~h}$, after which the solvent was evaporated under vacuum and the residue was purified by flash chromatography using hexanes and ethyl acetate $(6: 1, \mathrm{v} / \mathrm{v})$ to afford a mixture of $(\boldsymbol{E})$ - and $(\boldsymbol{Z})-\mathbf{5 a}(1.621 \mathrm{~g}, 96 \%)$ as a brown oil with a diastereomeric ratio of 2.3:1. ${ }^{1} \mathrm{H} \mathrm{RMN}\left(400 \mathrm{MHz}, \mathrm{CDCl}_{3}\right): \delta=7.57$ (d, $J=2.2$ $\mathrm{Hz}, 1 \mathrm{H}), 7.47(\mathrm{~d}, J=2.2 \mathrm{~Hz}, 1 \mathrm{H}), 7.32(\mathrm{~d}, J=16.6 \mathrm{~Hz}, 1 \mathrm{H}), 7.16(\mathrm{~d}, J=2.2 \mathrm{~Hz}, 1 \mathrm{H})$, $7.06(\mathrm{~d}, J=2.2 \mathrm{~Hz}, 1 \mathrm{H}), 7.03(\mathrm{~d}, J=12.0 \mathrm{~Hz}, 1 \mathrm{H}), 5.75(\mathrm{~d}, J=16.6 \mathrm{~Hz}, 1 \mathrm{H}), 5.34(\mathrm{~d}, J$ $=12.0 \mathrm{~Hz}, 1 \mathrm{H}), 5.26(\mathrm{~s}, 2 \mathrm{H}), 5.24(\mathrm{~s}, 2 \mathrm{H}), 5.21(\mathrm{~s}, 2 \mathrm{H}), 5.19(\mathrm{~s}, 2 \mathrm{H}), 3.66(\mathrm{~s}, 3 \mathrm{H}), 3.65$ (s, 3H), $3.53(\mathrm{~s}, 3 \mathrm{H}), 3.51(\mathrm{~s}, 3 \mathrm{H}), 1.43(\mathrm{~s}, 9 \mathrm{H}), 1.41 \mathrm{ppm}(\mathrm{s}, 9 \mathrm{H}) .{ }^{13} \mathrm{C}$ RMN $(100 \mathrm{MHz}$, $\left.\mathrm{CDCl}_{3}\right): \delta=150.7,150.5,150.0148 .9,148.7,148.6,143.9,143.8,128.6,128.5,122.5$, $121.0,118.6,117.9,115.0,112.5,99.3,99.3,95.5,95.4,94.8,93.4,57.9,57.9,56.5$, 56.6, 35.5, 35.3, 30.4, 30.3 ppm. IR (ATR): $v=3371.2,2953.8,2213.6,1615.5,1428.9$ $\mathrm{cm}^{-1}$. HRMS (ESI-QTOF): $\mathrm{m} / z$ calcd for $\mathrm{C}_{15} \mathrm{H}_{22} \mathrm{NaO}_{5}: 328.1519$; found: 328.1519 
Synthesis of $\mathbf{5 b}$. Synthesised from $\mathbf{4 b}$ using the same procedure as for $\mathbf{5 a}$. Yield $=72 \%$ with a diastereomeric $(E):(Z)$ ratio of 4.8:1. ${ }^{1} \mathrm{H} \mathrm{RMN}\left(400 \mathrm{MHz}, \mathrm{CDCl}_{3}\right): \delta=7.53(\mathrm{~d}, J$ $=2.1 \mathrm{~Hz}, 1 \mathrm{H}), 7.34(\mathrm{~d}, J=16.5 \mathrm{~Hz}, 1 \mathrm{H}), 7.23(\mathrm{~d}, J=2.1 \mathrm{~Hz}, 1 \mathrm{H}), 7.05(\mathrm{~d}, J=12.1 \mathrm{~Hz}$, $1 \mathrm{H}), 7.00(\mathrm{~d}, J=2.0 \mathrm{~Hz}, 1 \mathrm{H}), 6.88(\mathrm{~d}, J=2.0 \mathrm{~Hz}, 1 \mathrm{H}), 5.75(\mathrm{~d}, J=16.5 \mathrm{~Hz}, 1 \mathrm{H}, 4.39(\mathrm{~d}$ $J=12.1 \mathrm{~Hz}, 1 \mathrm{H}), 3.92(\mathrm{~s}, 3 \mathrm{H}), 3.92(\mathrm{~s}, 3 \mathrm{H}), 3.90(\mathrm{~s}, 3 \mathrm{H}), 3.88(\mathrm{~s}, 3 \mathrm{H}), 1.39(\mathrm{~s}, 9 \mathrm{H}), 1.37$ ppm (s, 9H). ${ }^{13} \mathrm{C}$ NMR $\left(100 \mathrm{MHz}, \mathrm{CDCl}_{3}\right) \delta=153.7,153.4,151.7,151.2,151.0,149.2$ $144.1,143.7,128.5,128.4,122.0,119.9,119.8,118.6,110.2,108.6,94.5,92.9,60.7$ $60.7,56.0,56.0,35.3,35.3,30.4,30.4 \mathrm{ppm}$. IR (ATR): $v=2952.0,2213.3,1615.6$, $1571.5,1415.0,1142.9,1067.0,1023.7 \mathrm{~cm}^{-1}$. HRMS (ESI-QTOF): $\mathrm{m} / z$ calcd for $\mathrm{C}_{15} \mathrm{H}_{19} \mathrm{NaNO}_{2}: 268.1308$, found: 268.1309 .

Synthesis of 6a. A mixture of (E)- and (Z)-5a (1.442 g, $4.8 \mathrm{mmol})$ and 10\% Pd/C (5:1, substrate/catalyst) in ethyl acetate $(16 \mathrm{~mL})$ was stirred at room temperature unde hydrogen atmosphere for $24 \mathrm{~h}$. Next, $\mathrm{Pd} / \mathrm{C}$ was filtered off and the solvent was removed in vacuo. The residue was purified by flash chromatography using hexanes and ethyl acetate $(3: 1, \mathrm{v} / \mathrm{v})$ to afford $6 \mathrm{a}(1.003 \mathrm{~g}, 68 \%)$ as a brown oil. ${ }^{1} \mathrm{H}$ RMN (400 MHz $\left.\mathrm{CDCl}_{3}\right): \delta=6.90(\mathrm{~d}, J=2.1 \mathrm{~Hz}, 1 \mathrm{H}), 6.84(\mathrm{~d}, J=2.1 \mathrm{~Hz}, 1 \mathrm{H}), 5.18(\mathrm{~s}, 2 \mathrm{H}), 5.16(\mathrm{~s}$ $2 \mathrm{H}), 3.64(\mathrm{~s}, 3 \mathrm{H}), 3.51(\mathrm{~s}, 3 \mathrm{H}), 2.88(\mathrm{t}, J=7.4 \mathrm{~Hz}, 2 \mathrm{H}), 2.58(\mathrm{t}, J=7.4 \mathrm{~Hz}, 2 \mathrm{H}), 1.4$ ppm (s, 9H) ${ }^{13} \mathrm{C}$ RMN $\left(100 \mathrm{MHz}, \mathrm{CDCl}_{3}\right): \delta 150.6,145.0,143.9,133.0,120.6,119.2$ $114.7,99.1,95.6,57.6,56.4,35.3,31.7,30.6,19.6 \mathrm{ppm}$. IR (ATR): $\mathrm{v}=2952.2,2904.6$ 2826.2, 2374.0, 1602.7, 1433.6, 1154.6, $936.8 \mathrm{~cm}^{-1}$. HRMS (ESI-QTOF): $\mathrm{m} / z$ calcd for $\mathrm{C}_{17} \mathrm{H}_{25} \mathrm{NaNO}_{4}$ : 330.1376; found: 330.1375 .

Synthesis of $\mathbf{6 b}$. Synthesised from $\mathbf{5 b}$ using the same procedure as for $\mathbf{6 a}$. Yield $=67 \%$ ${ }^{1} \mathrm{H}$ RMN $\left(400 \mathrm{MHz}, \mathrm{CDCl}_{3}\right): \delta=6.74(\mathrm{~d}, J=2.1 \mathrm{~Hz}, 1 \mathrm{H}), 6.69(\mathrm{~d}, J=2.1 \mathrm{~Hz}, 1 \mathrm{H})$ $3.86(\mathrm{~s}, 6 \mathrm{H}), 2.90(\mathrm{t}, J=7.4 \mathrm{~Hz}, 2 \mathrm{H}), 2.60(\mathrm{t}, J=7.4 \mathrm{~Hz}, 2 \mathrm{H}), 1.37 \mathrm{ppm}(\mathrm{s}, 9 \mathrm{H}) \cdot{ }^{13} \mathrm{C}$ RMN (100 MHz, $\left.\mathrm{CDCl}_{3}\right): \delta=171.5,153.7,148.0,144.0,133.0,119.7,119.0,111.0$ $60.8,56.0,35.0,32.2,30.9 \mathrm{ppm}$. IR (ATR): $v=2951.4,2866.4,2831.8,2245.0,1688.2$ $1580.1,1421.9,1346.7,1260.0,1067.6,1006.1 \mathrm{~cm}^{-1}$. HRMS (ESI-QTOF): $m / z$ calcd for $\mathrm{C}_{15} \mathrm{H}_{21} \mathrm{NaNO}_{2}$ : 270.1465; found: 270.1465 .

Synthesis of 7a. To a suspension of $\mathrm{LiAlH}_{4}(298 \mathrm{mg}, 7.9 \mathrm{mmol})$ in anhydrous $\mathrm{Et}_{2} \mathrm{O}(2$ $\mathrm{mL}$ ) cooled down in a water bath, a solution of $6 \mathbf{a}(695 \mathrm{mg}, 2.2 \mathrm{mmol})$ in anhydrous $\mathrm{Et}_{2} \mathrm{O}(2 \mathrm{~mL})$ was added dropwise. Next, the reaction mixture was stirred at room temperature for $14 \mathrm{~h}$ under inert atmosphere. The reaction mixture was cooled down to 0 ${ }^{\circ} \mathrm{C}$ and quenched with $\mathrm{NaOH} 1 \mathrm{M}(15 \mathrm{~mL})$. The resulting aqueous layer was extracted with $\mathrm{Et}_{2} \mathrm{O}(15 \mathrm{~mL})$ and $\mathrm{CHCl}_{3}(15 \mathrm{~mL})$. The combined organic extracts were dried with $\mathrm{MgSO}_{4}$ and the solvent removed in vacuo to afford $7 \mathbf{a}(627 \mathrm{mg}, 89 \%)$ as a yellowish oil. This product was used without further purification. ${ }^{1} \mathrm{H} \mathrm{RMN}\left(400 \mathrm{MHz}, \mathrm{CDCl}_{3}\right): \delta=$ $6.85(\mathrm{~d}, J=2.0 \mathrm{~Hz}, 1 \mathrm{H}), 6.80(\mathrm{~d}, J=2.0 \mathrm{~Hz}, 1 \mathrm{H}), 5.17(\mathrm{~s}, 2 \mathrm{H}), 5.16(\mathrm{~s}, 2 \mathrm{H}), 3.64(\mathrm{~s}$ $3 \mathrm{H}), 3.50(\mathrm{~s}, 3 \mathrm{H}), 2.73(\mathrm{t}, J=7.6 \mathrm{~Hz}, 2 \mathrm{H}), 2.58(\mathrm{t}, J=7.6 \mathrm{~Hz}, 2 \mathrm{H}), 1.74\left(\mathrm{q}_{\mathrm{t}}, J=7.6 \mathrm{~Hz}\right.$ 2H), $1.40 \mathrm{ppm}(\mathrm{s}, 9 \mathrm{H}) .{ }^{13} \mathrm{C} \mathrm{RMN}\left(100 \mathrm{MHz}, \mathrm{CDCl}_{3}\right): \delta=150.2,143.9,143.3,137.2$ 120.6, 114.7, 99.1, 95.5, 57.6, 56.4, 42.1, 35.7, 35.2, 33.4, 30.7 ppm. IR (ATR): v $3362.8,2949.4,1578.6,1431.9,1076.7,961.7 \mathrm{~cm}^{-1}$. HRMS (ESI-QTOF): $m / z$ calcd for $\mathrm{C}_{17} \mathrm{H}_{29} \mathrm{NNaO}_{4}$ : 334.1989; found: 334.1979 .

Synthesis of $\mathbf{7 b}$. Synthesised from $\mathbf{6 b}$ using the same procedure as for $\mathbf{7 a}$. Yield $=76 \%$ ${ }^{1} \mathrm{H}$ RMN (400 MHz, MeOD-d $)$ ): $\delta=6.74(\mathrm{~d}, J=2.0 \mathrm{~Hz}, 2 \mathrm{H}), 3.82(\mathrm{~s}, 3 \mathrm{H}), 3.80(\mathrm{~s}, 3 \mathrm{H})$ $2.70(\mathrm{t}, J=7.5 \mathrm{~Hz}, 2 \mathrm{H}), 2.58(\mathrm{t}, J=7.5 \mathrm{~Hz}, 2 \mathrm{H}), 1.79\left(\mathrm{q}_{\mathrm{t}}, J=7.5 \mathrm{~Hz}, 2 \mathrm{H}\right), 1.34 \mathrm{ppm}(\mathrm{s}$ 9H). ${ }^{13} \mathrm{C}$ RMN $\left(100 \mathrm{MHz}, \mathrm{MeOD}-\mathrm{d}_{4}\right): \delta=153.5,146.9,142.7,136.8,118.7,111.3$, $59.8,55.3,40.8,34.8,33.9,33.3,30.2 \mathrm{ppm}$. IR (ATR): $v=3452.3,2936.2,1578.1$ 1421.9, 1321.1, 1262.1, 1144.8, 1066.5, $1008.1 \mathrm{~cm}^{-1}$. HRMS (ESI-QTOF): $\mathrm{m} / z$ calcd for $\mathrm{C}_{15} \mathrm{H}_{25} \mathrm{NNaO}_{2}: 252.1958$; found: 252.1963 .

Synthesis of 8a. To a solution of 3-(naphthalen-1-ylamino)propanoic acid (646 mg, mmol), HOBt (589 mg, $4.3 \mathrm{mmol})$, EDCI ( $760 \mathrm{mg}, 3.9 \mathrm{mmol})$ and DIPEA (1.6 mL, 9.1 mmol) in $20 \mathrm{~mL}$ of anhydrous $\mathrm{CH}_{2} \mathrm{Cl}_{2}$, a solution of $7 \mathbf{a}(956 \mathrm{mg}, 3 \mathrm{mmol})$ in $10 \mathrm{~mL}$ of anhydrous $\mathrm{CH}_{2} \mathrm{Cl}_{2}$ was added. The reaction mixture was stirred at room temperature for $17 \mathrm{~h}$. Then, it was washed twice with a solution of saturated $\mathrm{NaHCO}_{3}(10 \mathrm{~mL})$ and once with a solution of saturated $\mathrm{NaCl}(10 \mathrm{~mL})$. The organic layer was dried with $\mathrm{MgSO}_{4}$ and solvent was evaporated under vacuum. Crude was purified by flash chromatography using hexanes and ethyl acetate $(1: 1, \mathrm{v} / \mathrm{v})$ to afford $8 \mathbf{a}(482 \mathrm{mg}, 31 \%)$ as a brown oil. ${ }^{1} \mathrm{H}$ RMN $\left(400 \mathrm{MHz}, \mathrm{CDCl}_{3}\right): \delta=7.81(\mathrm{~d}, J=8.1 \mathrm{~Hz}, 1 \mathrm{H}), 7.74(\mathrm{~d}, J=7.6 \mathrm{~Hz}, 1 \mathrm{H})$, $7.38-7.23(\mathrm{~m}, 4 \mathrm{H}), 6.79(\mathrm{~d}, J=1.9 \mathrm{~Hz}, 1 \mathrm{H}), 6.4(\mathrm{~d}, J=1.9 \mathrm{~Hz}, 1 \mathrm{H}), 6.58(\mathrm{~d}, J=7.6$ $\mathrm{Hz}, 1 \mathrm{H}), 6.04(\mathrm{~s}, 1 \mathrm{H}), 5.16(\mathrm{~s}, 2 \mathrm{H}), 5.11(\mathrm{~s}, 2 \mathrm{H}), 3.63(\mathrm{~s}, 3 \mathrm{H}), 3.54(\mathrm{t}, J=6.02 \mathrm{~Hz}, 2 \mathrm{H})$ $3.46(\mathrm{~s}, 3 \mathrm{H}), 3.24(\mathrm{dd}, J=13.1 \mathrm{~Hz}, J=6.7 \mathrm{~Hz}, 2 \mathrm{H}), 2.50(\mathrm{~m}, 4 \mathrm{H}), 1.73\left(\mathrm{q}_{\mathrm{t}}, J=7.6 \mathrm{~Hz}\right.$ $2 \mathrm{H}), 1.39 \mathrm{ppm}(\mathrm{s}, 9 \mathrm{H}) \cdot{ }^{13} \mathrm{C}$ RMN $\left(100 \mathrm{MHz}, \mathrm{CDCl}_{3}\right): \delta 171.9,150.1,143.4,143.1$ 136.23, 134.4, 128.6, 126.5, 125.9, 124.9, 123.9, 120.4, 117.8, 114.5, 104.5, 99.0, 95.4 $57.6,56.4,40.4,39.3,35.3,35.2,33.3,31.2,30.7 \mathrm{ppm}$. IR (ATR): $v=3304.4,2949.4$ $1638.2,1580.4,1526.7,1199.4,1035.5,961.9 \mathrm{~cm}^{-1}$. HRMS (ESI-QTOF): $\mathrm{m} / z$ calcd for $\mathrm{C}_{30} \mathrm{H}_{40} \mathrm{~N}_{2} \mathrm{NaO}_{5}: 531.2829$; found: 531.2834 .

Synthesis of $\mathbf{8 b}$ : Synthesised from $\mathbf{7 b}$ using the same procedure as for $\mathbf{8 a}$. Yield $=35 \%$. ${ }^{1} \mathrm{H}$ RMN (400 MHz, MeOD-d 4$): \delta=7.93(\mathrm{~d}, J=8.1 \mathrm{~Hz}, 1 \mathrm{H}), 7.69(\mathrm{~d}, J=7.9 \mathrm{~Hz}, 1 \mathrm{H})$ $7.41-7.23(\mathrm{~m}, 3 \mathrm{H}), 7.14(\mathrm{~d}, J=8.1 \mathrm{~Hz}, 1 \mathrm{H}), 6.69(\mathrm{~d}, J=2.9 \mathrm{~Hz}, 1 \mathrm{H}), 6.69(\mathrm{~s}, J=2.9$ $\mathrm{Hz}, 1 \mathrm{H}), 6.65(\mathrm{~s}, 1 \mathrm{H}), 6.60(\mathrm{~d}, J=4.3 \mathrm{~Hz}, 2 \mathrm{H}), 3.76(\mathrm{~s}, 3 \mathrm{H}), 3.69(\mathrm{~s}, 3 \mathrm{H}), 3.54$ (t, $J=$ $6.60 \mathrm{~Hz}, 2 \mathrm{H}), 3.17(\mathrm{t}, J=7.00 \mathrm{~Hz}, 3 \mathrm{H}), 2.59(\mathrm{t}, J=6.60 \mathrm{~Hz}, 2 \mathrm{H}), 2.53-2.45(\mathrm{~m}, 4 \mathrm{H})$ $1.73\left(\mathrm{q}_{\mathrm{t}}, J=7.6 \mathrm{~Hz}, 2 \mathrm{H}\right), 1.31 \mathrm{ppm}(\mathrm{s}, 9 \mathrm{H}) .{ }^{13} \mathrm{C}$ RMN (101 MHz, MeOD- $\left.\mathrm{d}_{4}\right): \delta 174.6$ $154.3,147.7,144.7,143.5,137.6,135.8,129.3,127.6,126.6,125.4,125.1,121.7,119.5$, $118.1,112.1,105.1,60.7,56.1,41.6,40.0,36.3,35.8,34.2,32.3,31.1 \mathrm{ppm}$. IR (ATR) $v=2919.5,2478.6,2065.58,1627.1,1577.7,1450.4,1420.8,1143.8,1067.9 \mathrm{~cm}^{-1}$ HRMS (ESI-QTOF): $m / z$ calcd for $\mathrm{C}_{28} \mathrm{H}_{36} \mathrm{~N}_{2} \mathrm{NaO}_{3}$ : 449.2799; found: 449.2804 .
Synthesis of 1. To a solution of $N$-ethyl-5-hydroxy-2-methyl-4-nitrosobenzenaminium chloride ( $72 \mathrm{mg}, 0.4 \mathrm{mmol}$ ) in $1 \mathrm{~mL}$ of $\mathrm{MeOH}$ cooled down in a water bath and under inert atmosphere, a solution of $\mathbf{8 a}(170 \mathrm{mg}, 0.33 \mathrm{mmol})$ in $1 \mathrm{~mL}$ of degassed $\mathrm{MeOH}$ and a 3 droplets of $\mathrm{HCl} 35 \%$ were added. This mixture was heated under reflux for $1.5 \mathrm{~h}$ Then it was cold down to room temperature and $\mathrm{CH}_{2} \mathrm{Cl}_{2}(5 \mathrm{~mL})$ and a mixture of saturated $\mathrm{NaCl}(2 \mathrm{~mL})$ and 3 droplets of $\mathrm{HCl} 35 \%$ were added. The resulting organic layer was washed twice with saturated $\mathrm{NaHCO}_{3}(3 \mathrm{~mL})$ and once with saturated $\mathrm{NaCl}(3$ $\mathrm{mL}$ ). Next, it was dried with $\mathrm{MgSO}_{4}$ and solvent was removed in vacuo. Crude was purified by flash chromatography using $\mathrm{CH}_{2} \mathrm{Cl}_{2}$ and $\mathrm{MeOH}(10: 1, \mathrm{v} / \mathrm{v})$ to afford 1 (87 $\mathrm{mg}, 45 \%$ ) as a bluish-violet solid. ${ }^{1} \mathrm{H}$ RMN (400 MHz, MeOD-d $\left.{ }_{4}\right): \delta=8.73$ (d, $J=8.1$ $\mathrm{Hz}, 1 \mathrm{H}), 8.22(\mathrm{~d}, J=8.1 \mathrm{~Hz}, 1 \mathrm{H}), 7.82(\mathrm{t}, J=7.5 \mathrm{~Hz}, 1 \mathrm{H}), 7.71(\mathrm{t}, J=7.5 \mathrm{~Hz}, 1 \mathrm{H})$ $7.51(\mathrm{~s}, 1 \mathrm{H}), 6.90(\mathrm{~s}, 1 \mathrm{H}), 6.70(\mathrm{~s}, 1 \mathrm{H}), 6.40(\mathrm{~s}, 1 \mathrm{H}), 6.38(\mathrm{~s}, 1 \mathrm{H}), 3.95(\mathrm{t}, J=6.2 \mathrm{~Hz}$ $2 \mathrm{H}), 3.49$ (q, $J=7.2 \mathrm{~Hz}, 3 \mathrm{H}), 3.21(\mathrm{~m}, 2 \mathrm{H}), 2.75(\mathrm{t}, J=6.2 \mathrm{~Hz}, 2 \mathrm{H}), 2.35(\mathrm{~m}, 2 \mathrm{H}), 2.29$ $(\mathrm{s}, 3 \mathrm{H}), 1.67\left(\mathrm{q}_{\mathrm{t}}, J=7.2 \mathrm{~Hz}, 2 \mathrm{H}\right), 1.46 \mathrm{ppm}(\mathrm{s}, 9 \mathrm{H}) .{ }^{13} \mathrm{C} \mathrm{RMN}\left(100 \mathrm{MHz}, \mathrm{MeOD}-\mathrm{d}_{4}\right): \delta$ $=172.9158 .2,156.9,152.5,149.3,145.7,143.3,136.8,133.9,132.9,132.6,132.5$, $132.4,132.3,130.7,129.0,125.5,124.5,123.6,118.2,113.5,94.5,94.1,41.9,40.3$, $39.8,35.8,34.0,32.5,30.1,17.8,14.2 \mathrm{ppm}$. IR (ATR): $v=3213.7,3076.2,2921.8$ $2852.5,1640.1,1587.6,1540.9,1433.8,1307.7,1160.8 \mathrm{~cm}^{-1}$. HRMS (ESI-QTOF): $\mathrm{m} / z$ calcd for $\mathrm{C}_{35} \mathrm{H}_{41} \mathrm{~N}_{4} \mathrm{O}_{4}^{+}: 581.3122$; found: 581.3124

Synthesis of 2. Synthesised from $\mathbf{8 b}$ using the same procedure as for $\mathbf{1}$. Yield $=35 \%$ ${ }^{1} \mathrm{H}$ RMN $\left(250 \mathrm{MHz}, \mathrm{MeOD}-\mathrm{d}_{4}\right): \delta 8.70(\mathrm{~d}, J=8.1 \mathrm{~Hz}, 1 \mathrm{H}), 8.20(\mathrm{~d}, J=8.1 \mathrm{~Hz}, 1 \mathrm{H})$, $7.81(\mathrm{t}, J=7.6 \mathrm{~Hz}, 1 \mathrm{H}), 7.70(\mathrm{t}, J=7.6 \mathrm{~Hz}, 1 \mathrm{H}), 7.48(\mathrm{~s}, 1 \mathrm{H}), 6.91(\mathrm{~s}, 1 \mathrm{H}), 6.70(\mathrm{~s}, 1 \mathrm{H})$ $6.51(\mathrm{~s}, 1 \mathrm{H}), 6.49(\mathrm{~s}, 1 \mathrm{H}), 4.56(\mathrm{~s}, 2 \mathrm{H}), 3.97(\mathrm{t}, J=5.9 \mathrm{~Hz}, 2 \mathrm{H}), 3.74(\mathrm{~s}, 3 \mathrm{H}), 3.70(\mathrm{~s}$ $3 \mathrm{H}), 3.49$ (q, $J=6.2 \mathrm{~Hz}, 2 \mathrm{H}), 3.22(\mathrm{t}, 2 \mathrm{H}, J=6.8 \mathrm{~Hz}, 2 \mathrm{H}), 2.77(\mathrm{t}, J=5.9 \mathrm{~Hz}, 2 \mathrm{H}$ ), $2.39(\mathrm{t}, J=6.8 \mathrm{~Hz}, 2 \mathrm{H}), 2.28(\mathrm{~s}, 3 \mathrm{H}), 1.68\left(\mathrm{q}_{\mathrm{t}}, J=6.8 \mathrm{~Hz}, 2 \mathrm{H}\right), 1.43-1.23 \mathrm{ppm}(\mathrm{m}$, $12 \mathrm{H}) .{ }^{13} \mathrm{C}$ RMN (63 MHz, MeOD-d 4$): \delta 173.0,158.2,156.8,154.3,152.5,149.2,147.8$ $143.6,140.2,137.4,133.9,132.9,132.6,132.2,130.7,129.0,125.5,124.5,123.6,119.4$ $114.7,112.1,94.5,60.7,56.2,41.9,40.2,39.8,35.7,34.9,34.2,33.0,32.4,31.9,31.1$ ppm. IR (ATR): $v=2920.8,2851.6,1640.4,1588.12,1541.4,1451.0,1310.0,1160.9$, 1133.6, 1006.6 cm $\mathrm{cm}^{-1}$. HRMS (ESI-QTOF): $\mathrm{m} / z$ calcd for $\mathrm{C}_{37} \mathrm{H}_{44} \mathrm{~N}_{4} \mathrm{NaO}_{4}: 609.3435$; found: 609.3435 .

Synthesis of M0. To a solution of di-tert-buthylcathecol $(107.2 \mathrm{mg}, 0.48 \mathrm{mmol})$ and 1,4-bis(imidazol-1-ylmethyl)benzene $(59.6 \mathrm{mg}, 0.25 \mathrm{mmol})$ in EtOH $(5 \mathrm{~mL}), 1 \mathrm{~mL}$ of an aqueous solution of $\mathrm{Co}\left(\mathrm{CH}_{3} \mathrm{COO}\right)_{2} \cdot 4 \mathrm{H}_{2} \mathrm{O}(61.7 \mathrm{mg}, 0.24 \mathrm{mmol})$ was added dropwise The mixture was stirred for $10 \mathrm{~min}$ and then the formation of nanoparticles was induced by fast addition of $25 \mathrm{~mL}$ of miliQ $\mathrm{H}_{2} \mathrm{O}$. Ligand excess was removed by centrifugation and the nanoparticles were washed three times with $\mathrm{H}_{2} \mathrm{O}$.

Synthesis of M1. To a solution of $1(5.5 \mathrm{mg}, 9.5 \mu \mathrm{mol})$, di-tert-buthylcathecol $(211.5$ $\mathrm{mg}, 0.95 \mathrm{mmol})$ and 1,4-bis(imidazol-1-ylmethyl)benzene $(117.3 \mathrm{mg}, 0.49 \mathrm{mmol})$ in $\mathrm{EtOH}(20 \mathrm{~mL}), 4 \mathrm{~mL}$ of an aqueous solution of $\mathrm{Co}\left(\mathrm{CH}_{3} \mathrm{COO}\right)_{2} \cdot 4 \mathrm{H}_{2} \mathrm{O}(121.4 \mathrm{mg}, 0.49$ $\mathrm{mmol}$ ) were added dropwise. The mixture was stirred for $10 \mathrm{~min}$ and then the formation of nanoparticles was induced by fast addition of $100 \mathrm{~mL}$ of miliQ $\mathrm{H}_{2} \mathrm{O}$. Ligand excess was removed by centrifugation and the nanoparticles were washed with a mixture of EtOH: $\mathrm{H}_{2} \mathrm{O}(\mathrm{v} / \mathrm{v}$ 1:5) until no red fluorescence was observed from the supernatant solution.

Synthesis of M2. To a solution of $2(3.1 \mathrm{mg}, 5.1 \mu \mathrm{mol})$, di-tert-buthylcathecol (120 mg, $0.53 \mathrm{mmol}$ ) and 1,4-bis(imidazol-1-ylmethyl)benzene (65 mg, $0.27 \mathrm{mmol})$ in EtOH (10 $\mathrm{mL}), 2 \mathrm{~mL}$ of an aqueous solution of $\mathrm{Co}\left(\mathrm{CH}_{3} \mathrm{COO}\right)_{2} \cdot 4 \mathrm{H}_{2} \mathrm{O}(68.9 \mathrm{mg}, 0.28 \mathrm{mmol})$ were added dropwise. The mixture was stirred for $10 \mathrm{~min}$ and then the formation of the nanoparticles was induced by fast addition of $50 \mathrm{~mL}$ of miliQ $\mathrm{H}_{2} \mathrm{O}$. Ligand excess was removed by centrifugation and the nanoparticles were washed with a mixture of EtOH: $\mathrm{H}_{2} \mathrm{O}(\mathrm{v} / \mathrm{v}$ 1:5) until no red fluorescence was observed from the supernatant solution.

Guest release experiments. A dialysis bag (cut-off molecular weight: 3500 ) containing M1 or $\mathbf{M} 2(\mathrm{c} \sim 3 \mathrm{mg} / \mathrm{mL})$ dispersed in phosphate buffered saline solution (PBS; $\mathrm{pH}=$ 7.4) was placed in $150 \mathrm{~mL}$ of $\mathrm{PBS}$ ( $\mathrm{pH}=7.4$; dialysate) at $37^{\circ} \mathrm{C}$ under light stirring. To determine the increase of $\mathbf{1}$ or $\mathbf{2}$ concentration diffused through the dialysis bag, $0.5 \mathrm{~mL}$ of external PBS solution were taken from the dialysate at prefixed times and diluted in 2 $\mathrm{mL}$ of $\mathrm{MeOH}$, and each aliquot was analyzed by fluorescence spectroscopy. The solid material remaining in the dialysis bag after 100 hours was dissolved in methanol and characterised by absorption spectroscopy

\section{Acknowledgements}

We acknowledge the financial support of the "Ministerio de Economía y Competividad" (MINECO) through projects MAT2012-38318-C03-02, MAT2012-38319-C02-01, CTQ2012-30853 and CTQ2010-15380. L.A.-F. thanks the "Universitat Autònoma de Barcelona" for a pre-doctoral grant.

[1] M. Oh, C.A. Mirkin, Nature, 2005, 438, 651-654.

[2] X. Sun, S. Dong, E. Wang, J. Am. Chem. Soc., 2005, 127, 13102-131103.

[3] A. M. Spokoyny, D. Kim, A. Sumrein, C. A. Mirkin, Chem. Soc. Rev., 2009, 38, 


\section{8-1227.}

[4] J. Della Rocca, D. Liu, W. Lin, Acc. Chem. Res., 2011, 44, 957-968.

[5] Z. Ma, B. Moulton, Coord. Chem. Rev., 2011, 255, 1623-1648.

[6] F. Novio, J. Simmchen, N.-A. Vázquez, L. Amorín, D. Ruiz-Molina, Coord Chem. Rev., in press (dx.doi.org/10.1016/j.ccr.2013.04.022).

[7] J. Siepmann, A. Göpferich, Adv. Drug Deliv. Rev., 2001, 48, 229-247.

[8] D. Y. Arifin, L. Y. Lee, C.-H. Wang, Adv. Drug Deliv. Rev., 2006, 58, $1274-$ 1325 .

[9] L. L. Lao, N. A. Peppas, F. Y. C. Boey, S. S. Venkatraman, Int. J. Pharm., 2011, $418,28-41$.

[10] W. J. Rieter, K. M. Pott, K. M. L. Taylor, W. Lin, J. Am. Chem. Soc., 2008, 130, 11584-11585.

[11] J. Yang, W. Liu, M. Sui, J. Tang, Y. Shen, Biomaterials, 2011, 32, 9136-9143.

[12] L. Xing, Y. Cao, S. Che, Chem. Commun., 2012, 48, 5995-5997.

[13] R. C. Huxford, K. E. de Krafft, W. S. Boyle, D. Liu, W. Lin, Chem. Sci., 2012 3, 198-204.

[14] K. Wang, X. Ma, D. Shao, Z. Geng, Z. Zhang, Z. Wang, Cryst. Growth Des., 2012, 12, 3786-3791.

[15] I. Imaz, J. Hernando, D. Ruiz-Molina, D. Maspoch, Angew. Chem. Int. Ed. 2009, 48, 2325-2329.

[16] I. Imaz, M. Rubio-Martínez, L. García-Fernández, F. García, D. Ruiz-Molina, J. Hernando, V. Puntes, D. Maspoch, Chem .Commun., 2010, 46, 4737-4739.

[17] P. Huang, J. Mao, L. Yang, P. Yu, L. Mao, Chem. Eur. J., 2011, 17, 1139011393.
[18] I. Imaz, D. Maspoch, C. Rodríguez-Blanco, J. M. Pérez-Falcón, J. Campo, D. Ruiz-Molina, Angew. Chem. Intl. Ed., 2008, 47, 1857-1860.

[19] a) E. Evangelio, D. Ruiz-Molina, Eur. J. Inorg. Chem., 2005, 2957-2971; b) D. N. Hendrickson, C. G. Pierpont, Top. Curr. Chem., 2004, 234, 63-95; c) P. Gütlich, A. Dei, Angew. Chem. Int. Ed., 1997, 36, 2734 - 2736.

[20] Q. Wang, Y. Yang, Y. Li, W. Yu, Z. J. Hou, Tetrahedron, 2006, 62, 6107-6112.

[21] D. A. Shultz, M. G. Hollomon, Chem. Mater. 2000, 12, 580-586.

[22] G. Bringmann, T. Pabst, S. Busemann, Tetrahedron, 1998, 54, 1425-14385.

[23] H. M. Kim, C. Jung, B. R. Kim, S-Y. Jung, J. H. Hong, Y-G. Ko, K. J. Lee, B. R. Cho, Angew. Chem. Int. Ed. 2007, 46, 3460-3463.

[24] S. A. Martin-Brown, Y. Fu, G. Saroja, M. M. Collinson, D. A. Higgins, Anal. Chem. 2005, 77, 486-494.

[25] V. H. J. Frade, M. S. T. Gonçalves, P. J. G. Coutinho, J. C. V. P. Moura, J. Photochem. Photobiol. A Chem., 2007, 185, 220-230.

[26] a) D. M. Adams, L. Noodleman, D. N. Hendrickson, Inorg. Chem. 1997, 36, 3966-3984; b) D. M. Adams, D. N. Hendrickson, J. Am. Chem. Soc. 1996, 118, 11515-11528.

[27] N. V. Anh, R. M. Williams, Photochem. Photobiol. Sci., 2012, 11, 957-961.

[28] a) J. Crank, The Mathematics of Diffusion, (Clarendon Press), Oxford, 1975. b) J. Siepmann, F. Siepmann, Int. J. Pharm., 2011, 418, $42-53$.

[29] a) H. B. Hopfenberg, in Controlled Release Polymeric Formulations, Vol 33 (Eds: D. R. Paul, F. W. Harris), ACS symposium Series 33, American Chemical Society, Washington, 1976, pp. 26-32.

[30] Z. Ramtoola, O. I. Corrigan, C. J. Barrett, J. Microencap., 1992, 9, 415-423.

[31] R. Sens, K. H. Drexhage, J. Luminesc., 1981, 24, 709-712.
Received: ((will be filled in by the editorial staff)) Revised: ((will be filled in by the editorial staff)) Published online: ((will be filled in by the editorial staff)) 


\section{Table of Contents}

Drug release mechanisms

uncovered!

Laura Amorín-Ferré, Félix Busqué, José Luis Bourdelande, Daniel Ruiz-Molina, Jordi Hernando*, Fernando Novio*

Encapsulation and Release

Mechanisms in Coordination

Polymer Nanoparticles
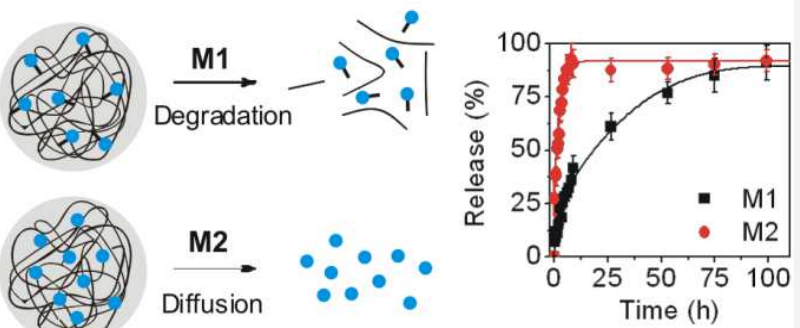

Coordination polymer nanoparticles loaded with coordinated and mechanically entrapped fluorescent guests were prepared as benchmark systems to investigate diffusion- and degradation-controlled drug delivery from these materials. 


\section{Supporting Information}

\section{Encapsulation and Release Mechanisms in Coordination Polymer Nanoparticles}

Laura Amorín-Ferré,${ }^{[\mathrm{a}]}$ Félix Busqué, ${ }^{[\mathrm{a}]}$ José Luis Bourdelande,${ }^{[\mathrm{a}]}$ Daniel Ruiz-Molina, ${ }^{[\mathrm{b}, \mathrm{c}]}$ Jordi Hernando $^{*[\mathrm{a}]}$, and Fernando Novio, ${ }^{*[\mathrm{~b}, \mathrm{c}]}$

${ }^{a}$ Departament de Química, Universitat Autònoma de Barcelona (UAB), Edifici C/n, Campus UAB, 08193 Cerdanyola del Vallès, Spain.Fax:+34035811265; E-mail: jordi.hernando@uab.cat

${ }^{b}$ Institut Català de Nanociència i Nanotecnologia (ICN2), Edifici ICN2, Campus UAB, 08193 Bellaterra, Spain.Fax: + 34 937372648; E-mail:fernando.novio@cin2.es

${ }^{c}$ Consejo Superior de Investigaciones Cientificas (CSIC), Edificio ICN2, Campus UAB, 08193 Bellaterra, Spain.

\section{Contents}

I. Characterisation of coordination polymer nanoparticles M0, M1 and M2

\section{Guest release experiments}




\section{Characterisation of coordination polymer nanoparticles M0, M1 and M2}
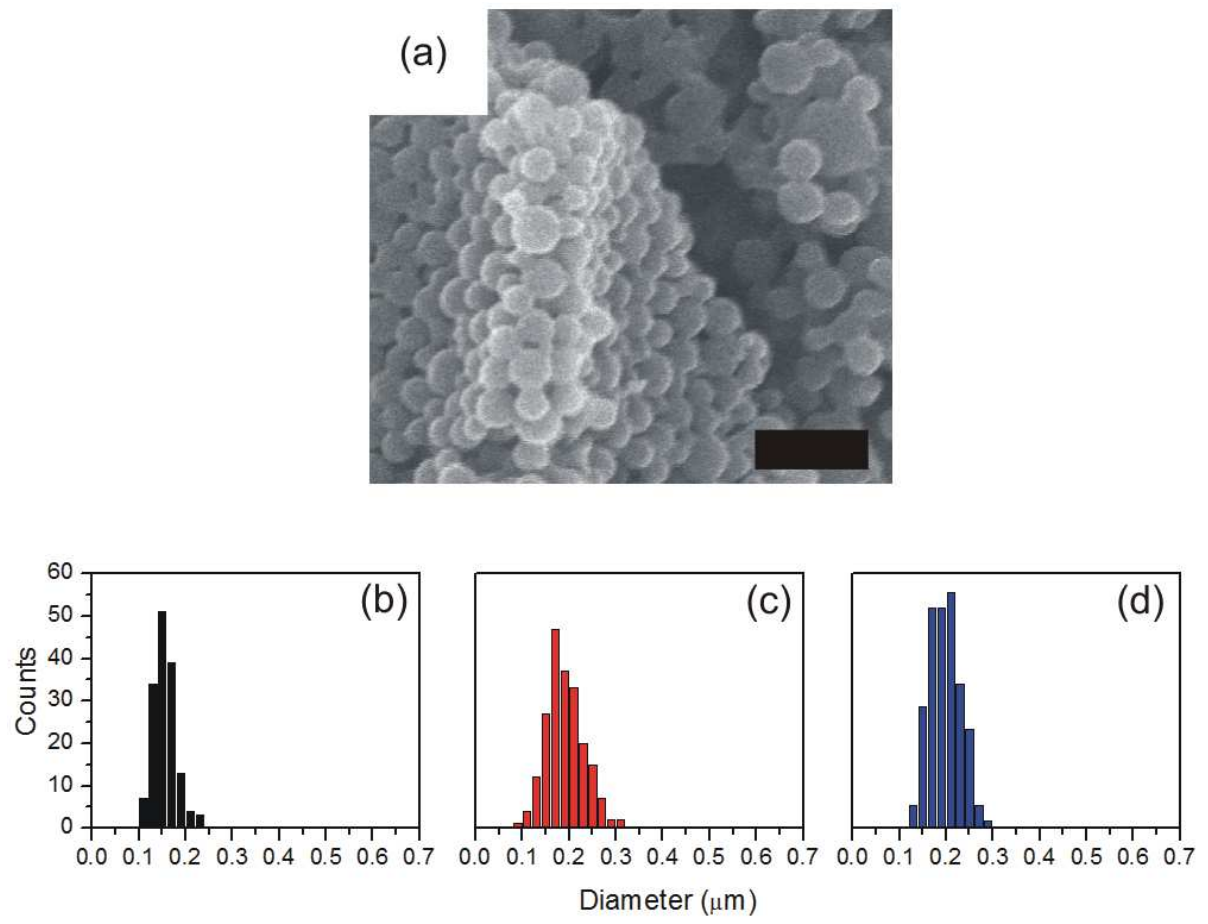

Figure S1. (a) SEM image of M0 nanoparticles. Scale bar is $500 \mathrm{~nm}$. Histograms of the size distribution of (b) M1, (c) M2 and (d) M0.

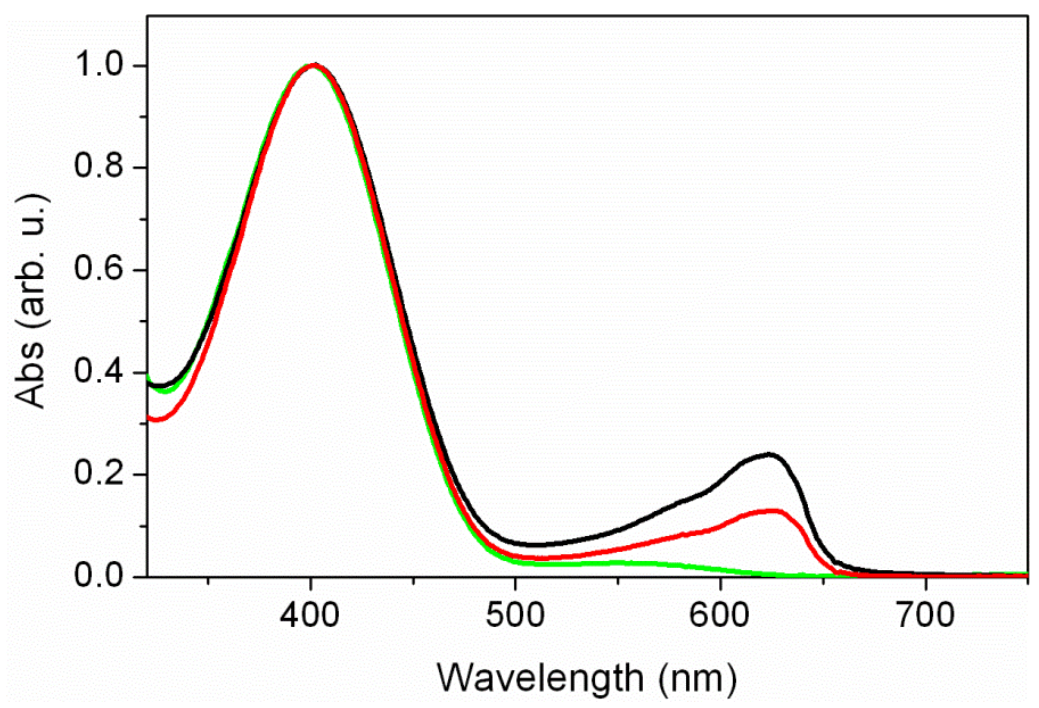

Figure S2.UV-vis spectra of M0 (green), M1 (black) and M2 (red) in non-degassed MeOH. 


\section{Guest release experiments}

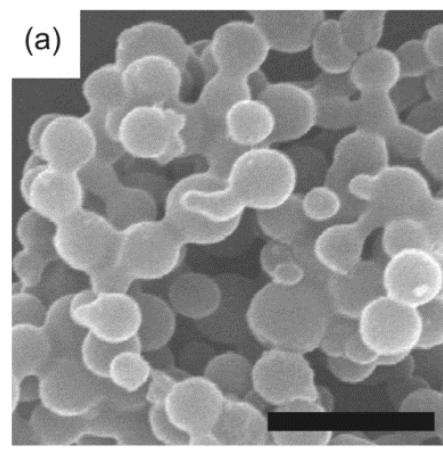

(b)
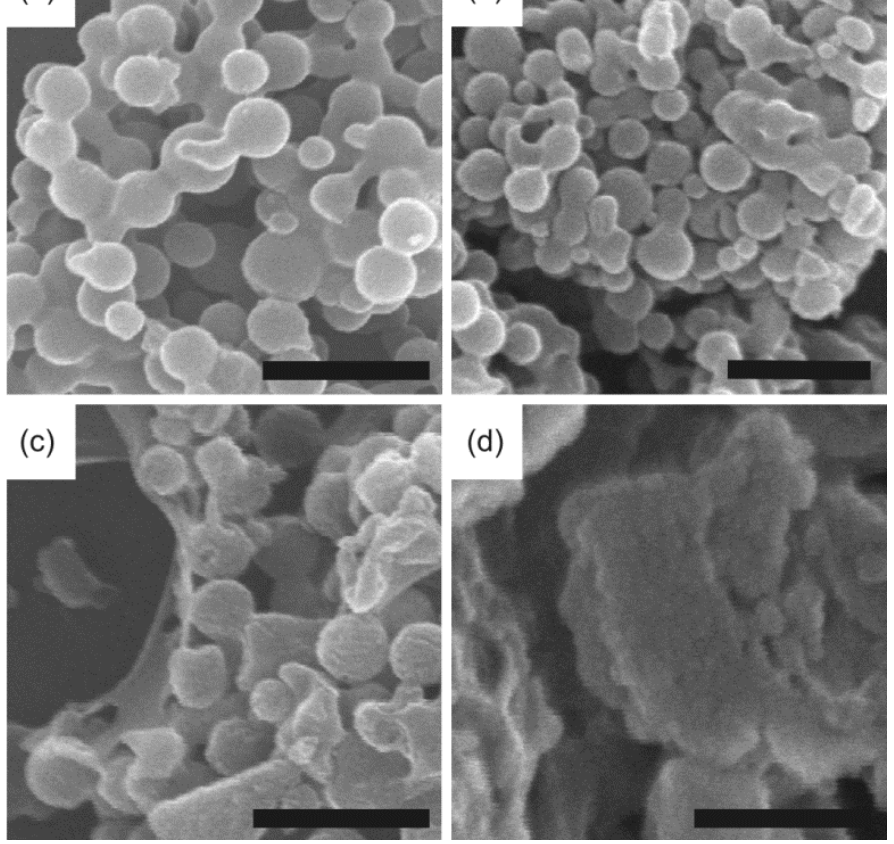

Figure S3. SEM images of M1 CPPs suspended in aqueous media at $37^{\circ} \mathrm{C}$ for (a) $0 \mathrm{~h}$, (b) $5 \mathrm{~h}$, (c) $26 \mathrm{~h}$ and (d) $100 \mathrm{~h}$. Scale bars are $500 \mathrm{~nm}$.

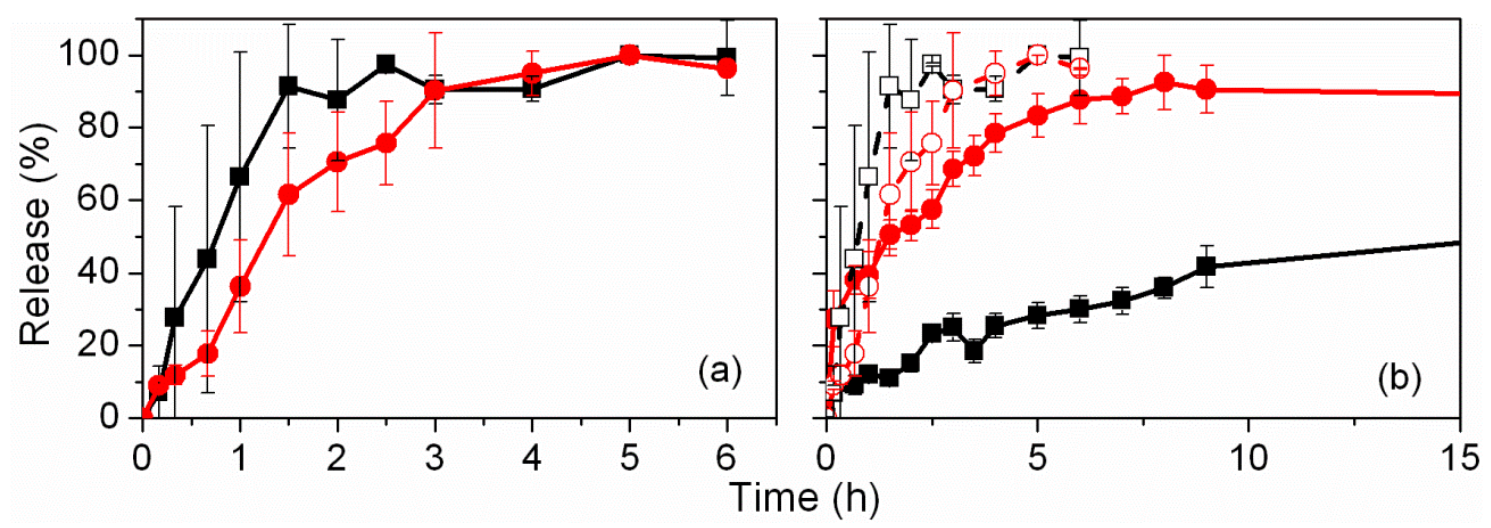

Figure S4. (a) Guest release profiles of fluorescent guest molecules from M1 (black) and M2 (red) at $60^{\circ} \mathrm{C}$. (b) Comparison of the guest release profiles measured for M1 (black) and $\mathbf{M 2}$ (red) at $37{ }^{\circ} \mathrm{C}$ (solid lines) and at $60{ }^{\circ} \mathrm{C}$ (dashed lines). 